\title{
EGFR confers exquisite specificity of Wnt9a-Fzd9b signaling in hematopoietic stem cell development
}

Stephanie Grainger ${ }^{1}$, Nicole Nguyen ${ }^{1}$, Jenna Richter ${ }^{1,2}$, Jordan Setayesh ${ }^{1}$, Brianna Lonquich ${ }^{1}$,

Chet Huan Oon ${ }^{1}$, Jacob M. Wozniak ${ }^{2,3,4}$, Rocio Barahona ${ }^{1}$, Caramai N. Kamei ${ }^{5}$, Jack Houston ${ }^{1,2}$, Marvic Carrillo-Terrazas ${ }^{3,4}$, Iain A. Drummond ${ }^{5,6}$, David Gonzalez $^{3.4}$, Karl Willert ${ }^{\sharp, ¥, 1}$, and David Traver $^{¥, 1,7}$.

${ }^{¥}$ co-corresponding authors: kwillert@ucsd.edu; dtraver@ucsd.edu

${ }^{\#}$ Lead contact

${ }^{1}$ Department of Cellular and Molecular Medicine, University of California, San Diego, La Jolla, California, 92037, USA.

${ }^{2}$ Biomedical Sciences Graduate Program, University of California, San Diego, La Jolla, California, 92037, USA.

${ }^{3}$ Skaggs School of Pharmacy and Pharmaceutical Science, University of California, San Diego, La Jolla, California, 92093, USA.

${ }^{4}$ Department of Pharmacology, University of California, San Diego, La Jolla, California, 92092

${ }^{5}$ Massachusetts General Hospital Nephrology Division, Charlestown, Massachusetts, 02129, USA.

${ }^{6}$ Harvard Medical School, Department of Genetics, Boston MA 02115

${ }^{7}$ Section of Cell and Developmental Biology, University of California, San Diego, La Jolla, California, 92037, USA.

Running title: A mechanism for Wnt-Fzd specificity in hematopoietic stem cells

Keywords: hematopoietic stem cell (HSC), Wnt, Wnt9a, human, zebrafish, Fzd, Fzd9b, FZD9, EGFR, APEX2 


\section{Summary:}

The mechanisms of Wnt-Frizzled (Fzd) signaling selectivity and their biological implications remain unclear. We demonstrate for the first time that the epidermal growth factor receptor (EGFR) is required as a co-factor for Wnt signaling. Using genetic studies in zebrafish, paired with in vitro cell biology and biochemistry, we have determined that Fzd9b signals specifically with Wnt9a in vivo and in vitro to elicit $\beta$-catenin dependent Wnt signals that regulate hematopoietic stem and progenitor cell (HSPC) development in the dorsal aorta. This requirement is conserved in the derivation of HSPCs from human embryonic stem cells. Wnt9a-Fzd9b specificity requires two intracellular domains in Fzd9b, which interact with EGFR as a required co-factor to promote signal transduction. EGFR phosphorylates one tyrosine residue on Fzd9b, a requirement for the $\mathrm{Wnt}$ signal. These findings indicate that $\mathrm{Wnt}$ signaling interactions can be exquisitely specific and inform protocols for derivation of HSPCs in vitro. 


\section{Highlights:}

- An in vitro signaling screen identifies Fzd9b as a Wnt9a-specific receptor.

- Fzd9b and Wnt9a regulate hematopoietic stem cell development as a cognate pair.

- WNT9A and FZD9 are required for HSPC derivation from human pluripotent cells in vitro.

- EGFR confers specificity to Wnt9a-Fzd9b signaling in zebrafish and human cells. 


\section{Introduction}

Members of the Wnt gene family encode highly conserved, lipid-modified glycoproteins that are involved in the regulation of a plethora of developmental processes including stem cell maintenance, proliferation and differentiation, as well as embryonic patterning and morphogenesis (reviewed in Loh et al., 2016). Although the mammalian genome encodes 19 Wnts and 10 Frizzled $(F z d)$ receptors, there is little evidence for signaling specificity through cognate Wnt-Fzd pairings (Cho et al., 2017). Previously, we established that Wnt9a is required specifically in zebrafish and human hematopoiesis, in that several other Wnt ligands could not replace the loss of Wnt9a (Grainger et al., 2016b; Richter et al., 2018). Using hematopoietic stem and progenitor cell (HSPC) development as a platform for validation, we demonstrate for the first time that the epidermal growth factor receptor (EGFR) is required as a co-factor to mediate the exquisite specificity of the WNT9A-FZD9 signaling interaction, a finding which may indicate a general paradigm for regulating Wnt-Fzd signaling specificity.

Hematopoietic stem cells (HSCs) are the tissue-specific stem cells that provide blood and immune cells for the duration of an organism's life. During development, these cells arise directly from major arterial vessels, from a specialized population of cells termed hemogenic endothelium (HE) (Bertrand et al., 2010; Cumano et al., 2001; Jaffredo et al., 1998; Kissa and Herbomel, 2010; Medvinsky and Dzierzak, 1996; Zovein et al., 2008). Prior to their emergence from the vasculature, cells of the HE are specified from mesodermal progenitors in the lateral plate mesoderm (Brown et al., 2000; Fouquet et al., 1997; Herbert et al., 2009; Jin et al., 2005; Liao et al., 1997). As these cells ingress beneath the somites, they receive inductive cues from developmental regulators, including fibroblast growth factors (FGF), Notch, and Wnt, to establish their fate and future function as aorta, vein, or HE from nearby tissues such as the somite and neural crest cells 
(Bertrand et al., 2010; Burns et al., 2005; Butko et al., 2015; Clements et al., 2011; Clements and Traver, 2013; Damm and Clements, 2017; Kobayashi et al., 2014; Leung et al., 2013; Wilkinson et al., 2009; Zhen et al., 2013). After their specification, HSPCs emerge directly from ventral endothelium comprising the dorsal aorta (hereafter aorta) in a process termed the endothelial-tohematopoietic transition (EHT) (Bertrand et al., 2010; Kissa and Herbomel, 2010). They then enter circulation and migrate to secondary hematopoietic organs such as the fetal liver in mammals, or the caudal hematopoietic tissue in teleosts, where they are thought to amplify and mature (Murayama et al., 2006; Tamplin et al., 2015) before seeding the final sites of hematopoietic residence in the bone marrow of mammals, or the kidney marrow of teleosts (Jagannathan-Bogdan and Zon, 2013).

Among the multiple inductive signals regulating HSC development and homeostasis are the growth factors encoded by the Wnt gene family (Baba et al., 2006; Fleming et al., 2008; Goessling et al., 2009; Kirstetter et al., 2006; Luis et al., 2012; Luis et al., 2011; Luis et al., 2009; Malhotra et al., 2008; Reya et al., 2003; Scheller et al., 2006; Willert et al., 2003; Zhao et al., 2007). We previously determined that an early Wnt9a cue drives a proliferative event in the aorta, after HSCs have emerged, but before they have seeded the secondary hematopoietic organs. Interestingly, this process cannot be mediated by other Wnt ligands, including Wnt3a or Wnt9b, suggesting exquisite specificity of Wnt ligand function, which may be mediated through specific interaction with one of the 14 zebrafish Fzd receptors (Grainger et al., 2016b).

Here, we identify Fzd9b as the cognate signaling partner for Wnt9a in the process of hematopoietic stem and progenitor cell (HSPC) development. Wnt9a and Fzd9b loss of function phenotypes in hematopoietic development are indistinguishable, and genetic complementation indicates that each operates in the same genetic pathway, upstream of $\beta$-catenin. This ligand- 
receptor pairing is conserved in human hematopoiesis in vitro, as determined using a previously established protocol to generate HSPCs ( $\mathrm{Ng}$ et al., 2008). A series of chimeric receptors between Fzd9b and a Fzd that does not promote Wnt9a signaling reveals that intracellular Fzd9b domains mediate the specificity of this Wnt-Fzd pairing, both in vitro and in vivo, indicating that a transmembrane spanning co-factor is involved in establishing specificity. Using a proximity ligation method followed by mass spectrometry (Hung et al., 2016; Lam et al., 2015), we identified the receptor tyrosine kinase EGFR as required for this specific signaling interaction for both zebrafish and human proteins. Altogether, these results demonstrate a conserved Wnt-Fzd pairing that mediates a precise Wnt cue required for hematopoiesis and opens the field for discovery of other Wnt-Fzd specificity co-regulators. 


\section{Results}

\section{Fzd9b interacts with Wnt9a in vitro}

We had previously established a specific requirement for Wnt9a in directing an early amplification of HSPCs, a surprising finding because Wnts have been thought to be functionally promiscuous (Grainger et al., 2016b; Ring et al., 2014; Voloshanenko et al., 2017). Vertebrate genomes encode multiple Fzd receptors, with $10 F z d$ genes in mammals and $14 f z d$ genes in zebrafish, suggesting that one mechanism for specific Wnt function involves specific Wnt-Fzd pairing. Wnt9a signals from the somite to ingressing HE prior to 20 hours post fertilization (hpf) (Grainger et al., 2016b). A screen for $f z d$ expression in 16.5 hpf flila-positive cells indicated that a majority of Fzds were expressed in the ingressing endothelial cell population (Fig. S1A-B). To narrow down the number of potential Wnt9a receptors, we employed an established $\beta$-catenin dependent Wnt reporter assay (Veeman et al., 2003), called Super-TOP-Flash (STF). Wnt9a alone induced low levels of STF reporter activity; however, upon co-transfection with Fzd5 and Fzd9b, but no other Fzd, Wnt9a significantly increased STF reporter activity (Fig. S1C-D, Fig. 1A). Since we hypothesized that Wnt9a would signal to its cognate receptor on neighboring cells, we used a co-culture approach to assess the ability of Wnt9a to act in a paracrine manner on Fzd5 and Fzd9b. In this co-culture assay, Fzd9b, but not Fzd5, was able to transduce the Wnt9a signal and activate STF reporter activity (Fig. 1B-C), indicating that Fzd9b acts as a specific Wnt9a receptor. Taken together, these results indicate that Fzd9b is able to transduce the Wnt9a signal in vitro, suggesting that Fzd9b is involved in Wnt9a-mediated HSC development.

\section{Fzd9b is required for zebrafish hematopoiesis}


Since somite-derived Wnt9a signals to ingressing HE prior to $20 \mathrm{hpf}$, we hypothesized that $f z d 9 b$ would be expressed in cells of the HE prior to this. By whole-mount in situ hybridization (WISH) or double-fluorescent whole-mount in situ hybridization (FISH) at $15 \mathrm{hpf}$, we detected $f z d 9 b$ in neural tissues, in the anterior lateral plate mesoderm, which contains endothelial cells contributing mostly to primitive hematopoiesis (Detrich et al., 1995; Holz et al., 2003; Zhang and Rodaway, 2007), and in the medial and posterior lateral plate mesoderm, the tissues from which HE is derived (Maeno et al., 1985; Pardanaud et al., 1996; Turpen et al., 1981) (Fig. 2A). FISH for $f z d 9 b$ and the endothelial marker flila confirmed that $f z d 9 b$ is expressed in endothelial precursor cells (Fig. 2B). To test if hematopoietic cells were derived from cells expressing $f z d 9 b$, we performed a lineage tracing experiment using $f z d 9 b$ promoter sequences driving expression of Gal4 in two ways. First, Gal4 can activate an upstream activating sequence (UAS) driven GFP (fzd9b:Gal4;UAS:GFP); secondly UAS:Cre can be similarly activated, which ultimately leads to recombination of loxP sites flanking a BFP, and expression of dsRed (fzd9b:Gal4; UAS:Cre; loxP BFP loxP dsRed) Using this strategy, with which we were able to observe GFP-positive or dsRed-positive (pseudo colored as green here) cells in the floor of the dorsal aorta in the characteristic cup shape seen during the EHT (at $40 \mathrm{hpf}$ ), indicating that nascent HSPCs had expressed $f z d 9 b$ prior to their emergence (Fig. 2C, Fig. S2A). T-cells derived from HSCs reside in the thymus beginning around 4 days post-fertilization (dpf) and expressed GFP at 6 and 7 dpf (Fig. 2D, Fig S2B), consistent with a function for $f z d 9 b$ in HSPC development.

The initial specification of HSPCs in wnt $9 a$ morphants is normal at $28 \mathrm{hpf}$, but later proliferative events are disrupted around 32-40 hpf (Grainger et al., 2016b). These phenotypes would be expected to be recapitulated by disruption of the Wnt9a receptor. To assess the function of Fzd9b in hematopoiesis, we used a translation-blocking morpholino (MO), which was able to 
block translation of a fluorescently labelled Fzd9b in vivo (Fig. S2C-D). Consistent with wnt9a loss of function, WISH for the early HSC marker runxl indicated that hematopoietic specification was not affected in $f z d 9 b$ morphants (Fig. S2E). We confirmed these findings using reverse transcription-quantitative PCR (qPCR) on trunks and tails of morphants and sibling controls (Fig. $\mathrm{S} 2 \mathrm{~F}$ ), indicating that Fzd9b is not required for hematopoietic specification. The expansion of hematopoietic cells is defective in wnt9a mutants and morphants, as determined by WISH for HSPC markers at 40 hpf (Grainger et al., 2016b); likewise, cmyb positive cells were significantly reduced in the dorsal aorta of $f z d 9 b$ morphants at $40 \mathrm{hpf}$. These findings were consistent with a reduction of cmyb and runxl at 40 hpf by qPCR (Fig. 2E-G). In addition, loss of $f z d 9 b$ led to a loss of emerging HSPCs, as indicated by confocal imaging of gata2b/kdrl double positive cells in the floor of the dorsal aorta at 46 hpf (Fig. S2G-I) (Butko et al., 2015). This loss of early HSPCs persisted throughout development, where ragl+ thymocytes ( $\mathrm{T}$ cell precursors derived from HSPCs) were reduced in $f z d 9 b$ morphants (Fig. S2J-K). This effect was specific to HSPCs, as markers for aorta $(d l c, d l l 4$, notchlb), vasculature $(k d r l)$ and pronephros (cdh17) were normal (Fig. S2L-U). The $f z d 9 b$ MO could be rescued with $f z d 9 b$ mRNA (Fig. S2V-Y), suggesting that the effects of the MO were specific.

To validate our MO findings, we used CRISPR/Cas9 to generate two germline mutants of $f z d 9 b$, each of which had predicted premature stop codons early in the $f z d 9 b$ coding sequence, harboring either a 2-base insertion, or a 7-base deletion, and both predicted to produce severely truncated N-terminal proteins of approximately 30 amino acid residues. Consistent with our MO findings, $f z d 9 b$ mutants had a reduction in cmyb+ cells at $40 \mathrm{hpf}$ (Fig 2H-I). Finally, we used a previously described transgenic approach where a guide RNA to $f z d 9 b$ is expressed ubiquitously and $\operatorname{Cas} 9$ expression is spatially regulated by $U A S$ to conditionally inactivate $f z d 9 b$ in early 
endothelial cells (Ablain and Zon, 2016), which also led to a reduction in the number of $c m y b+$ cells at $40 \mathrm{hpf}$ (Fig. 2J-K), indicating that Fzd9b is required in the endothelium for HSPC development. Taken together, these results indicate Fzd9b is required for HSPC development, downstream of fate specification, and specifically in endothelial cells.

\section{Fzd9b interacts genetically with Wnt9a}

We previously showed that Wnt9a's effect on hematopoietic development required $\beta$-catenin (commonly referred to as the canonical Wnt pathway)(Grainger et al., 2016b). We therefore hypothesized that loss of $f z d 9 b$, the putative Wnt9a receptor, could be rescued with overexpression of constitutively-active (CA) $\beta$-catenin. Indeed, expression of CA- $\beta$-catenin under regulatory control of a gata $2 b$ promoter region (expressed exclusively within HE) was sufficient to rescue loss of $f z d 9 b$ (Fig. 3A-E), indicating that like Wnt9a, Fzd9b functions upstream of $\beta$-catenin. The assembly of Fzd-Lrp5/6 heterodimers in response to a Wnt ligand is critical to enable signal transduction in $\beta$-catenin dependent signaling (Tamai et al., 2000). Consistent with Wnt9a-Fzd9b operating upstream of $\beta$-catenin, the Wnt9a-Fzd9b signal could be synergistically increased in vitro in cells co-transfected with Lrp6 (Fig. S3A). To determine if Wnt9a-Fzd9b signaling was reliant on endogenous LRP6 expression, we generated a HEK293T STF line deficient for LRP6 using CRISPR/Cas9. The resultant cell line harbored three alleles with large deletions in exon 2 of LRP6, which encodes part of the first extracellular beta-propeller, leading to a complete loss of protein as assessed by immune-blotting (Fig. 3F). These LRP6-deficient cells were compromised in their ability to activate STF reporter activity upon Wnt3a addition (Fig. S3B); however, treatment with GSK3 inhibitor (CHIR98014), which activates downstream signaling independent of Wnt-Fzd-LRP interactions, stimulated STF activity, indicating that downstream signaling 
components were intact (Fig. S3C). Consistent with these results, Wnt9a-Fzd9b signaling also required LRP6 (Fig. 3G). Therefore, the Wnt9a-Fzd9b complex operates upstream of $\beta$-catenin.

To confirm that Wnt9a and Fzd9b function in the same pathway in vivo, we used genetic non-complementation with suboptimal MO dosages. We found that a low dose of either Wnt9a or Fzd9b MO was not sufficient to affect hematopoiesis, while compound morphant animals had a reduction in $c m y b+$ cells similar to either wnt $9 a$ or $f z d 9 b$ loss of function, providing genetic evidence that these components operate in the same genetic pathway (Fig. 3H-L). Altogether, these data indicate that Wnt9a and Fzd9b function in the same genetic pathway, upstream of $\beta$ catenin.

\section{WNT9A and FZD9 contribute to human hematopoietic development in vitro}

Having identified a specific Wnt9a-Fzd9b signal in vivo in zebrafish, we sought to identify an interaction partner for human WNT9A. Using the STF reporter assay as above, we determined that only FZD9 coupled effectively with WNT9A (Fig. 4A), indicating that this signaling specificity is conserved from fish to human. To determine the requirement for WNT9A and FZD9 in human hematopoietic development, we employed an established differentiation protocol to drive human embryonic stem (hES) cell lines towards hematopoietic fates (Ng et al., 2008) (Fig. 4B). Previously, we showed that WNT9A promotes this differentiation, as monitored by expression of CD34, CD45 and RUNX1 (Richter et al. 2018). Disrupting WNT9A or FZD9 expression using short hairpin RNAs (shRNAs) significantly compromised the ability of hES cells to generate CD34/CD45 double positive HSPCs (Fig. 4C-F), suggesting that WNT9A and FZD9 contribute to human HSPC derivation. These results were confirmed with qPCR for endothelial 
(CD34) and hematopoietic markers $(C D 31, C D 45, C M Y B)$ (Fig. S4A-D). Differences in the abilities of these cells to differentiate were not due to loss of pluripotency of the undifferentiated hES cells, as they still abundantly expressed the pluripotency markers TRA1-81 and SSEA4 (Cooper et al., 2002; Thomson et al., 1998)(Fig. S4E-G). Thus, WNT9A and FZD9 are required for in vitro HSPC development in human cells.

\section{Wnt9a-Fzd9b specificity is mediated intracellularly}

How the Wnt-Fzd signaling complex relays its signal and establishes specificity is poorly understood. One possibility is that Wnts engage the extracellular domains of Fzds with varying affinities. The crystal structure of a Wnt in complex with the extracellular domain of Fzd indicated that the Wnt molecule makes multiple contacts with the cysteine rich domain (CRD) (Janda et al., 2012). Furthermore, a number of studies showed that Wnts interact with varying affinities with the CRD (Dijksterhuis et al., 2015; Rulifson et al., 2000). Using the STF assay system and zebrafish cDNAs, we assessed the requirement for the Fzd9b CRD in mediating the Wnt9a signal in vitro and found that in the absence of the Fzd9b CRD, the Wnt9a-Fzd9b signal was attenuated (Fig. 5A), consistent with previous findings that the CRD is required for Wnt9a-Fzd9b signaling.

We next sought to determine which domain(s) are required for Wnt9a-Fzd9b signaling specificity by constructing a series of chimeric Fzd transgenes between Fzd9b and Fzd8a, a Fzd that did not couple with Wnt9a to activate STF reporter activity (Fig. 1A). Surprisingly, a chimeric receptor in which the CRD of Fzd8a was replaced with that of Fzd9b did not signal (Fig. 5B), while the chimeric Fzd9b receptor carrying the Fzd8a CRD produced wild-type Wnt9a signaling activity (Fig. 5B), suggesting that the identity of the CRD is not a critical determinant in coupling 
Wnt9a-Fzd9b signaling. Furthermore, these results suggest that other domains of Fzd are critical in conferring Wnt9a specificity.

The signaling events downstream of Wnt-Fzd interaction and oligomerization with Lrp are poorly understood but are thought to involve interaction with intracellular mediator proteins such as Disheveled (Dsh), which is thought to interact with Fzd at the third intracellular loop (ICL3) and the C-terminal tail (CTT) (Tauriello et al., 2012; Wong et al., 2003). To assess the role of the ICL3 and CTT in mediating Wnt9a-Fzd9b signaling, we generated further Fzd9b-Fzd8a chimeric constructs (Fig. 5B). Using this approach, we found that substituting out either the ICL3 or CTT from Fzd9b with those of Fzd8a was sufficient to dampen signaling, while introducing these domains from Fzd9b into Fzd8a modestly increased the signal (Fig. 5B). Substituting both the ICL3 and CTT from Fzd9b with those from Fzd8a completely ablated the signal, and conversely substituting these Fzd9b domains into Fzd8a was sufficient to produce wild-type signaling levels (Fig. 5B), suggesting that signaling specificity for Wnt9a-Fzd9b lies entirely within the ICL3 and CTT domains. We were also able to recapitulate these findings using zebrafish and human cDNAs encoding chimeras for Fzd9b/FZD9 and Fzd4/FZD4 in our STF assay (Fig. S5A-B), indicating that the ICL3 and CTT are required for zebrafish Fzd9b and human FZD9 signaling.

As the Fzd protein matures and is exported to the cell surface, post-translational modifications including glycosylation increase the molecular weight (Janda et al., 2012; MacDonald and He, 2012; Yamamoto et al., 2005). Using V5-tagged Fzd constructs, we found that there was no change in the ability of these chimeric constructs to mature or be modified posttranslationally (Fig. S5C). To confirm that the chimeric Fzd9b constructs that did not signal were transported to the cell surface, we performed immunofluorescence (IF) with a Fzd9b antibody directed to the extracellular the region between the CRD and the first transmembrane domain of 
Fzd9b (Fig. S5D). IF using this antibody on non-permeabilized cells confirmed that chimeric Fzd9b proteins were expressed on the cell surface at levels similar to wild-type Fzd9b (Fig. S5E). We further confirmed these findings using flow cytometry (Fig. S5F), indicating that differences in signaling were not due to differences in Fzd protein expression, maturation, or transport to the cell surface.

Altogether, these data indicated that ICL3 and CTT mediate the Wnt9a-Fzd9b signaling specificity in vitro. To determine if these domains were able to fulfill Fzd9b function in HSPC development, we co-injected mRNAs for $f z d 9 b, f z d 8 a$ or $f z d 8 a$ with the ICL3 and CTT from $f z d 9 b$ in the context of $f z d 9 b \mathrm{MO}$ and found that only $f z d 9 b$ and $f z d 8 a$ with the ICL3 and CTT from $f z d 9 b$ were able to rescue loss of $f z d 9 b$ (Fig. 5C-H). Taken together, these data indicate that Wnt9aFzd9b specificity is regulated by the intracellular ICL3 and CTT domains of Fzd9b.

\section{Wnt9a, Fzd9b and EGFR form a complex}

Since the above data indicate that Wnt9a-Fzd9b specificity is mediated intracellularly, we postulated the existence of another signaling component that spanned the membrane and contacted both Wnt9a and the intracellular portion of Fzd9b. Since we were able to analyze Wnt9a-Fzd9b signaling specificity using zebrafish cDNAs in human cells, we furthermore hypothesized that this signaling component would be a highly conserved. Therefore, to determine which proteins are recruited to the ICL3 and CTT of Fzd9b in response to Wnt9a, we generated a stable HEK293T cell line harboring Fzd9b fused to the peroxidase APEX2 (Lam et al., 2015). In the presence of hydrogen peroxide and biotin-phenol, endogenous proteins proximal to APEX2 (generally within 
$30 \mathrm{~nm}$ ) are biotinylated, allowing for their enrichment with streptavidin beads, and subsequent identification by mass spectrometry (Lam et al., 2015). Due to the short labeling time required (60 seconds), it is possible to generate a timeline of proteins recruited to Fzd9b in response to Wnt9a. The APEX2 labelling from these cells was specific to biotin-phenol and hydrogen peroxide induction (Fig. S6A). Notably, the fusion protein did not interfere with membrane localization of Fzd9b (Fig. S6B-C) and was able to signal in response to Wnt9a as determined with STF reporter activity (Fig. S6D).

Gene ontology $(\mathrm{GO})$ analysis of our APEX data revealed that in response to Wnt9a, the most changed biological processes included ERBB signaling (Fig. S6E). Consistent with this observation, the transmembrane proteins most enriched by proximity labeling were EGFR (also known as ERBB1), and ERBB2 (Fig. S6F). Disrupting EGFR expression in HEK293T cells stably expressing Fzd9b with short interfering RNA (siRNA) reduced cell surface binding of Wnt9a (Fig. $6 \mathrm{~A}-\mathrm{H})$, suggesting that EGFR plays a role in the Wnt9a-Fzd9b interaction. Consistent with this observation, the EGFR ligand blocking antibody Cetuximab (Doody et al., 2007) dampened the Wnt9a-Fzd9b signal (Fig. 6I). These data are consistent with a model in which EGFR forms a complex with Wnt9a and Fzd9b to transmit the Wnt signal.

\section{EGFR is required for the Wnt9a-Fzd9b signal}

Genes from ERBB family, including EGFR, encode single-pass transmembrane receptor tyrosine kinases that homo- and hetero-dimerize in response to multiple ligands and to stimulate a number of signaling cascades (Mishra et al., 2017). HEK293T cells transfected with a short interfering RNA (siRNA) to EGFR compromised the ability of both zebrafish and human Wnt9a/WNT9A and Fzd9b/FZD9 to stimulate STF reporter activity (Fig. S6G, Fig 6J-K). Similarly, using a 
previously validated MO to egfra (Zhao and Lin, 2013), we observed a decrease in the number of HSPCs at 40 hpf, similar to the phenotypes of $f z d 9 b$ or wnt $9 a$ loss of function, and consistent with a role for Egfr in regulating the Wnt9a-Fzd9b signal (Fig. 6L-N). In addition, suboptimal MO dosing indicated that both Fzd9b and Wnt9a operate in the same pathway as Egfr during HSPC development (Fig. 6O). Furthermore, treatment of cells with the selective EGFR tyrosine kinase inhibitor AG1478 (Goishi et al., 2003; Osherov and Levitzki, 1994) significantly attenuated STF reporter activity of both zebrafish Wnt9a/Fzd9b and human WNT9A/FZD9 (Fig. S6H-I). Consistent with these results, EGFR kinase activity was also required for HSC development in zebrafish, as assayed by expression of the HSC markers runxl and gata2b at $40 \mathrm{hpf}$ (Fig. S6J). These data indicate EGFR and its kinase activity are required for the Wnt9a-Fzd9b signal.

EGFR is known to cross-talk with other seven-pass transmembrane receptors such as Gprotein coupled receptors (GPCRs), the consequences of which have effects on signal transduction, as well as receptor internalization and trafficking (Daub et al., 1997; Gschwind et al., 2001; Kue et al., 2002; Prenzel et al., 1999; Schafer et al., 2004; Tomlins et al., 2005; Vacca et al., 2000). Consistent with this, GO analysis of our APEX data indicated that the most enriched cellular component was "clathrin-coated endocytic vesicle" (Fig S6K). The APEX data also showed enrichment for proteins associated with early endosomes (RAB5A, RAB5B, RAB5C and RAB14), late endosomes (RAB7A, RAB9A and RAB12), and recycling endosomes (RAB11B, RAB35 and RAB13) (Fig. 6P), consistent with Fzd9b internalization in response to Wnt9a (Fig. 6I). Internalization of seven-pass transmembrane proteins can be mediated by clathrin- or caveolinmediated endocytosis, as can Fzd-Wnt complexes (Blitzer and Nusse, 2006; Yamamoto et al., 2006). We observed the recruitment of members of the AP-2 complex and clathrin-mediated endocytosis machinery to Fzd9b in response to Wnt9a, indicating that internalization was mediated 
by clathrin (Fig. 6Q). Finally, both the zebrafish Wnt9a/Fzd9b and human WNT9A/FZD signals required clathrin-mediate endocytosis, as indicated by STF assay after treatment with the clathrin inhibitor chlorpromazine (Fig. 6R-S). These results indicate that Fzd9b is internalized and sorted through the endosome-lysosome in response to Wnt9a.

The C-terminal tail of Fzd9b contains two tyrosine (Y) residues, at 556 and 571 (Fig. 7A), which are predicted to be potential kinase substrates (Blom et al., 1999). Additionally, the Y556 on Fzd9b is highly conserved among vertebrates and Y571 is partially conserved, indicative of putative functional importance (Fig. S7A). Consistent with these predictions, treatment with Wnt9a increased Y-phosphorylation of Fzd9b (Fig. 7B). This increase was not observed in the presence of the EGFR tyrosine kinase inhibitor AG1478 (Fig. S7D), indicating that EGFR kinase activity is required to increase Y-phosphorylation on Fzd9b in response to Wnt9a. In addition, mutation of the Y556 (but not Y571) putative phosphorylation sites decreased the in vitro signaling capacity of Wnt9a (Fig. 7C). Finally, mutation at the corresponding tyrosine in human FZD9, Y562F, also led to a decrease in its signaling capacity (Fig. S7D), suggesting that this function is conserved. Together, these data indicate that Fzd9b is phosphorylated on tyrosine residue 556 in response to Wnt9a, which is required for its downstream signal.

Taken together, our data suggest a mechanism for the specificity of Wnt9a-Fzd9b signaling. Fzd9b, LRP6 and EGFR are resident in proximity at the cell surface (Fig. 7Di); in the absence of a ligand, $\beta$-catenin is targeted for proteasomal degradation by the destruction complex (Fig. 7Dii); in the presence of Wnt9a, these are bridged, allowing EGFR-mediated phosphorylation of the Fzd9b tail at Y556 (Fig. 7Fiii), leading to the recruitment of AP-2 and clathrin (Fig. 7Div). Once inside the cell, Fzd9b-LRP6 oligomerization leads to dissociation of the destruction complex 
bioRxiv preprint doi: https://doi.org/10.1101/387043; this version posted August 7, 2018. The copyright holder for this preprint (which was not certified by peer review) is the author/funder. All rights reserved. No reuse allowed without permission.

Grainger, et al, 2018

and release of $\beta$-catenin (Fig. 7Dv). Finally, nuclear $\beta$-catenin transactivates a program for HSC proliferation (Fig. 7Dvi). 


\section{Discussion}

EGFR and Fzd9b are required for the Wnt9a signal in vitro and in vivo

We have found that Fzd9b is required to relay the Wnt9a signal during HSPC development in zebrafish; this finding shows conservation to human cells as well, where WNT9A and FZD9 are required to generate HSPCs from human pluripotent precursors. We have determined that the specificity of the Wnt9a-Fzd9b (and the WNT9A-FZD9) signal relies on intracellular domains, not the extracellular CRD, suggesting the existence of a transmembrane co-factor. With a proximity-labeling based mass spectrometry approach, we identified that EGFR and Fzd9b are closely associated in the cell; EGFR (and specifically the tyrosine kinase activity) is also required for HSPC development and for the Wnt-Fzd9b signal. Altogether, these results suggest a general paradigm where particular Wnt-Fzd interactions mediate specific signals that are transduced in the context of particular co-receptors, such as receptor tyrosine kinases.

Our previously characterized requirement for Wnt9a in HSPC development had established that Wnt9a plays a specific role in the early amplification of HSPCs, which could not be rescued by other Wnts (Grainger et al., 2016b). Here we showed that this extracellular Wnt9a signal is relayed in vitro and in vivo by Fzd9b (or FZD9 in humans) and not by any other Fzd receptor. The requirement for Fzd9 in blood development is in line with previous data from mouse models, where loss of Fzd9 leads to a partially cell-intrinsic hematopoietic defect (Ranheim et al., 2005). Although the authors did not examine HSPCs directly, they did note several pathologies linked to HSPCs, such as depletion of B cells (one of the lymphoid lineages downstream of HSCs), splenomegaly, thymic atrophy and lymphadenopathy with age (Ranheim et al., 2005). These observations are consistent with a loss of HSPCs during development. Furthermore, disruption of FZD9 expression has been linked to hematological malignancies, highlighting its importance in 
human hematopoietic cells as well (Jiang et al., 2009; Martin-Subero et al., 2009; Zhang et al., 2016). For instance, FZD9 was identified as one of 6 genes most frequently hypermethylated in hematological neoplasms (Martin-Subero et al., 2009). In another example, FZD9 was identified as the most frequently aberrantly methylated gene in a survey of 184 patients with myelodysplastic syndrome and acute myeloid leukemia; those with loss of heterozygosity of the FZD9 allele had the poorest outcome (Jiang et al., 2009). Altogether, these data point to a role for Fzd9 in hematopoietic stem cell development.

The identification of EGFR contributing to HSPC development is surprising. There is little evidence for the involvement of EGFR in the hematopoietic niche. Loss of EGFR results in midgestational mortality in mice, precluding the analysis of HSPCs (Sibilia and Wagner, 1995). EGFR has been shown to promote the recovery of HSPCs in response to radiation injury (Doan et al., 2013); conversely, inhibition of EGFR promotes the mobility of HSPCs (Ryan et al., 2010). These are in general support of a role of EGFR in HSPCs that has not yet been explored, and consistent with our findings that it is required as a co-factor during HSPC development.

\section{A model for Wnt-Fzd signaling specificity}

One long outstanding puzzle in the Wnt field has centered around the requirement for genetically encoding such a diverse set of ligands and receptors if Wnt ligands are as promiscuous as reported (Dijksterhuis et al., 2015; Ring et al., 2014; Yu et al., 2012). In addition, biochemical analysis of Wnt/Fzd interactions has been limited since Wnt purification is difficult, due to post-translational modifications making them highly hydrophobic (Willert et al., 2003). Finally, putative functional overlap between family members has made determination of specific function and cognate pairings 
hard to deconvolute using genetics (Ikeya et al., 1997; Ikeya and Takada, 1998; Yamaguchi et al., 2005). Therefore, potential pairings have remained elusive.

It has been hypothesized that Wnt-Fzd interactions are regulated by physical binding affinities. Xenopus Wnt8 interacts directly with the CRD of mouse Fzd8, as shown by x-ray crystallography (Janda et al., 2012). In addition, dissociation constant measurements of Wnt-CRD interactions revealed that different Wnt-Fzd combinations have different affinities and that many Wnts can physically interact with multiple (if not all) Fzd CRDs (Dijksterhuis et al., 2015; Hsieh et al., 1999; Ring et al., 2014; Yu et al., 2012). This has led to the prevailing model that Wnt ligands are promiscuous, signaling with any Fzd in proximity. This model has been supported in large part due to the fact that the prototypical ligand, Wnt3a was first to be purified, and is in fact able to activate a multitude of Fzd receptors in vitro (Dijksterhuis et al., 2015; Voloshanenko et al., 2017; Willert et al., 2003). In addition, the low solubility of Wnts leads to a very short secretion range, which predicts that Wnt-Fzd specificity is regulated largely at the level of spatio-temporal expression (Farin et al., 2016). Our results indicate that signaling specificity is regulated at an additional level involving the activation of co-receptors, though this does not preclude specificity contributions from secretion range, spatio-temporal localization or Wnt-Fzd affinities.

We have shown that Fzd9b is present in the membrane in proximity to its co-receptor EGFR, which has previously been shown to be membrane localized in an inactive conformation in the absence of a ligand (Purba et al., 2017). Once Wnt9a is present, EGFR phosphorylates tyrosine residues on the CTT of Fzd9b and leads to the recruitment of internalization machinery such as the AP-2 complex and clathrin. LRP6 is also required for this signaling event, as previously established for other $\beta$-catenin dependent signaling events (Baig-Lewis et al., 2007; Cong et al., 2004; Pinson et al., 2000; Schweizer and Varmus, 2003; Tamai et al., 2000; Wehrli et 
al., 2000). We therefore propose that the signaling specificity of a Wnt-Fzd pair is regulated (1) by the ability of Wnt to bind to the Fzd CRD, and (2) the recruitment of an activating co-receptor required for internalization (Fig. 7D). This combination of internalization and LRP recruitment then leads to nuclear $\beta$-catenin accumulation and target gene activation.

This model is in general agreement with the finding that Fzds have putative phosphorylation sites, and can be phosphorylated upon activation, though this has only been shown in the context of $\beta$-catenin independent signaling (Djiane et al., 2005; Shafer et al., 2011; Yanfeng et al., 2006). This is also in general agreement with the so called "endosomal Wnt signaling" model, which posits that Fzd-LRP6 oligomerization, phosphorylation and subsequent caveolinmediated endocytosis are required for signaling, while clathrin-mediated endocytosis would result in signal dampening (Yamamoto et al., 2006; Yamamoto et al., 2008). In contrast, we have found that clathrin-mediated endocytosis is initiated following Fzd9b phosphorylation by EGFR, indicating that clathrin-mediated endocytosis can also lead to context-dependent signal activation. Of note, caveolin dependent endocytosis is characterized by the presence of caveolin-1, which we did not detect in our APEX data (Parton and Simons, 2007). This finding may also explain the puzzle of how Drosophila, which lack caveolin, but do have clathrin, are able to produce a Wnt signal (MacDonald and He, 2012), as well as how caveolin $^{-/-}$mice have augmented Wnt signaling in certain niches ( $\mathrm{Li}$ et al., 2005; Sotgia et al., 2005). On the other hand, clathrin-mediated endocytosis has been shown to be required for Drosophila Wg (Wnt homologue) internalization and signaling in vitro (Blitzer and Nusse, 2006), which is also consistent with our findings. These differences in clathrin- and caveolin-mediated endocytosis leading to up- or down-regulation of signaling may relate back to the particular Wnt/Fzd/co-receptor combination activating their 
recruitment, since particular phosphorylation signatures are known to affect sorting of the endosome (Villasenor et al., 2016).

This model is also in agreement with findings of EGFR transactivation with other sevenpass transmembrane receptors such as GPCRs (Kose, 2017). Others have hypothesized that Fzd receptors are a sub-class of GPCRs (Dijksterhuis et al., 2014); there is limited, but growing evidence for Fzd receptor coupling to $\mathrm{G}$ proteins, although this is debated in the field (Ahumada et al., 2002; Halleskog et al., 2012; Katanaev, 2010; Katanaev et al., 2005; Kilander et al., 2014a; Kilander et al., 2011a; Kilander et al., 2011b; Kilander et al., 2014b; Liu et al., 2001; Liu et al., 1999; Sheldahl et al., 1999; Slusarski et al., 1997). Regardless of whether or not Fzds are true GPCRs, this does not preclude them from functioning in a manner similar to GPCRs. GPCR desensitization is regulated by internalization of the receptor, a process that is dependent on posttranslational modifications such as phosphorylation (Jean-Charles et al., 2016). In our study, we have found that Fzd9b is phosphorylated on tyrosine residues in response to Wnt9a, consistent with a role for the receptor tyrosine kinase EGFR in this process. Altogether, these indicate that in response to Wnt9a, Fzd9b is phosphorylated by EGFR, and internalized through clathrinmediated endocytosis. There is precedent for this particular mechanism of internalization of receptors. For example, trafficking of the GPCR CXCR7 requires serine/threonine phosphorylations at the C-terminus, followed by deubiquitination, which is likely required to allow interaction with AP-2 (Canals et al., 2012). Wnt signaling also depends on clathrin-mediated endocytosis in a context-dependent manner (Saito-Diaz et al., 2018). Finally, Wnt7a and Wnt7b signaling depend on the membrane anchored glycoprotein Reck and the GPCR Gpr124 together with Fzd4 (Cho et al., 2017; Eubelen et al., 2018; Zhou and Nathans, 2014), while Norrin and Fzd4 signaling relies on Tspan12 (Lai et al., 2017), supporting the notion that specificity of Wnt-Fzd 
pairs relies on co-receptor complexes. In particular, low level affinities of Reck for Wnt7 seems to be important for regulating the availability for Wnt7 to bind its cognate Fzd receptor, through oligomerization with Gpr124, Dishevelled and Fzd (Eubelen et al., 2018).

There are many families of receptor tyrosine kinases, including EGFR/ERBB, FGF receptors, vascular endothelial growth factor receptors and Eph receptors, among others. Of these, many are known to play complementary roles with Wnt signaling during development and cancer. For example, Wnt10b and FGF3 cooperate in mammary tumorigenesis (Lee et al., 1995), as do FGF8 and Wnt1 (MacArthur et al., 1995). In planarians, Wnt and FGFR are both required for anterior-posterior patterning of the brain (Kobayashi et al., 2007) and chondrocyte differentiation (Buchtova et al., 2015). In addition to these, there are overlapping functions for Wnt and FGF in the developing pre-somitic mesoderm, with consequences in somitogenesis and axial elongation (reveiwed in Mallo, 2016). It is conceivable that activation of these receptors in the context of a Fzd may also play a cooperative role in activation of the Wnt signal.

\section{Wnt-Fzd co-receptors in regenerative medicine and cancer}

One context where knowledge of Wnt-Fzd and co-factor specific interactions will be critical will be in regenerative medicine, such as in the development of protocols to derive different tissues in vitro from pluripotent precursor cells. Although there is increasing evidence for HSC derivation in vitro (Sturgeon et al., 2013; Wahlster and Daley, 2016), the field still struggles with deriving HSCs in vitro from pluripotent precursors, using xenograft-free conditions. This would allow for patient-specific cell therapies for diseases of the blood such as leukemias, lymphomas, anemias, and auto-immune disorders. In large part, the requirement for $\beta$-catenin dependent Wnt signaling in these protocols has been substituted for with the prototypical ligand, Wnt3a, or with GSK3 
inhibitors, which potently activate Wnt signaling. Our data suggest that certain biological functions of the Wnt signal cannot be substituted for with other Wnt agonists; for example, the loss of Wnt9a during early HSPC proliferation in zebrafish cannot be rescued by Wnt3a (Grainger and Richter et al, 2016b). Additionally, the complement of Fzd receptors and putative co-receptors expressed in the correct spatio-temporal location will be essential to recapitulating endogenous developmental cues in the dish. The hematopoietic field has struggled for decades to make bona fide HSCs in vitro from either conversion of non-hematopoietic cells or directed differentiation from pluripotent precursors. Many efforts to reprogram non-hematopoietic human or mouse cells directly to HSCs resulted in HSPC-like cells that could not be sustained in vivo (Batta et al., 2014; Doulatov et al., 2013; Elcheva et al., 2014; Pereira et al., 2013; Pulecio et al., 2014; Sandler et al., 2014). However, long-term, engraftable, immunocompetent HSCs can now be derived by direct conversion of mouse endothelial cells, using a set of four transcription factors using mouse cells (Lis et al., 2017). A similar approach has also been used in human cells derived from pluripotent precursors; however, the therapeutic use of these is challenged by exogenous expression of transcription factors (Sugimura et al., 2017). One potential issue may be overlooking this early proliferative event, for example, along with the requirement for FZD9 and EGFR as co-receptors in this process, as this strategy uses the general GSK3 $\beta$ inhibitor CHIR99021 (Dege and Sturgeon, 2017; Ditadi and Sturgeon, 2016; Sugimura et al., 2017). Taking these specific requirements into consideration will be critical to the advancement of regenerative medicine.

Cross talk between WNT and EGFR has been long observed, especially in cancer cells, though the molecular mechanisms regulating this process have been poorly understood, but are thought to operate at multiple levels (Paul et al., 2013). For instance, EGFR activating mutations are associated with better prognosis when coupled with unmethylated Wnt antagonist promoter 
regions (Suzuki et al., 2007), suggesting that these Wnt antagonists may influence EGFR activity. EGF-mediated activation of EGFR leads to an increase in $\beta$-catenin transcriptional activity in cancer cells (Ji et al., 2009), as does expression of activated variants of EGFR (Del Vecchio et al., 2012). Wnt1 and Wnt5a are thought to induce cyclinDl expression through EGFR activation in mammary $\mathrm{HC} 11$ epithelial cells, which could be blocked using a ligand blocking antibody to EGFR (Civenni et al., 2003); an alternate explanation to these findings could be aberrant EGFRmediated endocytosis coupled to the Fzd receptor that is mediating the Wnt signal. It has also been suggested that this occurs through direct Y-phosphorylation of $\beta$-catenin by various receptor tyrosine kinases (Krejci et al., 2012), though the cooperation between these receptor tyrosine kinases and Wnt transcriptional output could also be re-interpreted at the level of the membrane.

EGFR and Wnt have also been suggested to cross-talk during normal development and homeostasis. For instance, EGFR signaling, similar to Wnt, is required for re-establishing the proximal-distal axis during leg regeneration in crickets, where RNAi loss of function phenocopies the loss of Wnt (Nakamura et al., 2008). There is also evidence for Wnt/EGFR function in Drosophila spiracle development (Maurel-Zaffran et al., 2010), hemocytes (Zettervall et al., 2004), glucose homeostasis (Cardone et al., 2012) and epithelial regeneration (Georgopoulos et al., 2014), among others.

Finally, determining how individual WNTs and FZDs are coupled will have important therapeutic implications. Overactivation of the WNT pathway is associated with a number of human malignancies, including (but not limited to) cancers of lungs, ovaries, breast, skin, brain and intestinal tract (Clevers and Nusse, 2012). In some subsets of these cancers, different FZD receptors are overexpressed, leading to an amplification of the WNT signal (Chan and Lo, 2018; Ueno et al., 2013). Importantly, pan-WNT inhibitory therapies cause toxic side effects, due to the 
importance of WNT signaling in other tissues, such as the maintenance of the intestinal epithelium (Korinek et al., 1998; Schepers and Clevers, 2012; van Es et al., 2012). Furthermore, our observation that Cetuximab, which blocks ligand binding to EGFR, disrupts Wnt9a/Fzd9 signaling suggests potential alternative mechanisms of action for this chemotherapeutic agent. Being able to derive therapies that are specific to WNT-FZD pairs will allow for more specific targeting of these cancer cells. 


\section{Experimental Procedures:}

\section{Cell culture and luciferase reporter assays}

HEK293T cells with a stably integrated Super-TOP-Flash reporter (STF) (Fernandez et al., 2014) and Chinese hamster ovary $(\mathrm{CHO})$ cells were grown in Dulbecco's modified Eagle's medium (DMEM) supplemented with $10 \%$ heat-inactivated fetal bovine serum (FBS) under standard conditions.

Cells were seeded into six-well plates and transfected using polyethyleneimine (PEI), 50ng of renilla reporter vector, 200ng of Wnt, Fzd or Lrp6 expression vector, with a total of 1 ug of DNA/well. For co-culture experiments, cells were passaged 24 hours after transfection and plated together for analysis. For siRNA experiments, a 6 well was treated with 10pmol of siRNA using RNAiMax transfection reagent (Invitrogen). All human WNT9A cell culture experiments except for the initial screen were performed by co-culturing stably expressing WNT9A CHO cells with stably expressing FZD9 HEK293 STF cells. All transfected cells were harvested 48 h posttransfection and all conditioned medium or co-cultured cells were harvested $24 \mathrm{~h}$ post-treatment; the lysates processed and analyzed using the Promega Dual Luciferase Assay System according to the manufacturer's instructions. Each experiment was performed with biological triplicate samples and reproduced at least one time with a similar trend.

$10 \mathrm{~cm}$ plates of $293 \mathrm{~T}$ cells were transfected with $10 \mathrm{ug}$ of constructs encoding chimeric Fzd cDNAs with a C-terminal V5 tag. For immunofluorescence, cells were plated onto glass coverslips after 24 hours, and stained with our Fzd9b antibody, generated to a region between the CRD and the first transmembrane domain, under non-permeabilized conditions, and according to standard 
protocols. For flow cytometry, cells were harvested with Accutase, pelleted, resuspended in PBS with $1 \%$ BSA and 1mM EDTA, filtered through an 80um filter and sorted using a BD Fortessa flow cytometer. For western blots, cells were harvested 48 hours after transfection in TNT buffer (1\% Triton $\mathrm{X}-100,150 \mathrm{mM} \mathrm{NaCl}, 50 \mathrm{mM}$ Tris, pH8.0), with protease inhibitors. Westerns were performed according to standard procedures, using antibodies for V5 (1:5,000, GeneTex) and $\beta$ $\operatorname{actin}(1: 20,000$, Abcam).

For immunoprecipitation, cells were washed 3 times in PBS and lysed in radio immunoprecipitation assay (RIPA) buffer (10mM Tris-HCl, pH8, 10mM EDTA, 0.5mM EGTA, $1 \% \mathrm{Tx}-100,0.1 \%$ deoxycholate, $0.1 \% \mathrm{SDS}, 140 \mathrm{mM} \mathrm{NaCl}$ ), supplemented with protease and phosphatase inhibitor tablets (Pierce) and $20 \mathrm{mM} \mathrm{N}$-ethylmaleimide, for 30 minutes at $4^{\circ} \mathrm{C}$ with rocking. Resultant lysates were cleared of cell debris by centrifugation at $15,000 \mathrm{~g}$ for 10 minutes at $4^{\circ} \mathrm{C}$ and quantified by Bradford Assay. A minimum of $200 \mathrm{ug}$ of protein was diluted into $400 \mathrm{uL}$ total volume with RIPA buffer; $2 \mathrm{ug}$ of antibody was added and incubated at room temperature for 30-60 minutes. Antibody-protein complexes were precipitated using Protein a Dynabeads (Invitrogen) for 30 minutes at room temperature, washed 3 times with $1 \mathrm{~mL}$ of RIPA buffer and eluted using Laemmli buffer at room temperature. Precipitates were run on a Western blot for Fzd9b. Western blot intensities from pulldowns were quantified by densitometry using ImageJ, normalized to input controls.

EGFR inhibition was performed using a 5mM stock of AG1478 in 50:50 Ethanol: DMSO. The final concentration used was 2.5uM. Clathrin-mediated endocytosis was inhibited using chlorpromazine from a $1 \mathrm{M}$ stock in 50:50 Ethanol: DMSO. Final concentrations used are as 
indicated in the figure. The Human EGFR phosphorylation Array C1 (Raybiotech) was carried out according to the manufacturer's recommendations using lysates from Fzd9b-mKate HEK293T cells treated with Wnt9a or mock conditioned medium for 1 minute.

\section{Wnt9a surface binding assay}

Conditioned medium was collected from stably expressing Wnt9a or parental CHO cells and concentrated 10X using a 30kDa molecular weight cutoff column. HEK293T cells stably expressing Fzd9b were transfected with siControl or siEGFR and plated on $0.1 \%$ gelatin coated glass coverslips after 24 hours; after a further 24 hours, cells were treated with cold conditioned medium for 3 hours at $4^{\circ} \mathrm{C}$, rinsed with PBS and fixed with $4 \%$ PFA at $4{ }^{\circ} \mathrm{C}$ for 20 minutes and at room temperature for 10 minutes. Immunofluorescence was performed using standard nonpermeabilizing methods with a rabbit polyclonal antibody generated to zebrafish Wnt9a.

\section{Generation of LRP6 knockout HEK293T STF line}

A confluent 100mm plate of HEK293T STF cells were transfected with 3mg each of Cas9 (Jao et al., 2013) and two guide RNAs under regulatory control of a U6 promoter. The guide RNAs (GGGCTTGGAGGATGCAGCTG and GGATCTAAGGCAATAGCTCT) targeted the second exon of LRP6. Single cell clones were validated for loss of LRP6 by sequencing the genomic locus, Western blot using a rabbit monoclonal antibody (1:1000, C47E12, Cell Signaling) and for loss of LRP6 function with STF assay for mouse Wnt3a, which is reliant on LRP6 for signaling (Tamai et al., 2000).

\section{Fzd9 and Wnt9a antibody generation}


GST fusion proteins for immunogens of Fzd9b (provide amino acid numbers) and Wnt9a (provide amino acid numbers) were purified by standard methods. Rabbits were immunized with GST proteins, boosted and bled for serum according to standard methods (Lampire Biologicals). Antibodies for Wnt9a or Fzd9b were affinity purified against the same antigens fused to maltose binding protein (MBP), according to the manufacturer's recommendations (Fisher), and stored in PBS $/ 50 \%$ glycerol at $-80^{\circ} \mathrm{C}$.

\section{Zebrafish lines and maintenance}

Zebrafish were maintained and propagated according to University of California and local Institutional Animal Care and Use Committee policies. AB*, $\operatorname{Tg}(k d r l \text { :Cherry-CAAX })^{y 171}$, Tg(flila:eGFP) $)^{z 5544}, \quad T g(c d h 5: G a l 4)^{m u 101}, \quad T g(U A S: C A-\beta \text {-catenin })^{\text {sd47Tg }} \quad T g\left(\right.$ gata2b:KalTA4 ${ }^{\text {sd } 32}$; UAS:Lifeact:eGFP $\left.P^{m u 271}\right), \quad$ wnt9a $a^{\Delta 28 / \Delta 28, s d 49}, \quad T g(U A S: C r e)^{t 32240 T g} \quad T g($ bactin2:loxP-BFP-loxPDsRed $)^{s d 27 T g}$ lines have been previously described (Bertrand et al., 2010; Bertrand et al., 2008; Bouldin and Kimelman, 2014; Butko et al., 2015; Espin-Palazon et al., 2014; Grainger et al., 2016b; Jin et al., 2005; Kobayashi et al., 2014; Lawson and Weinstein, 2002; Lewis et al., 2004; Mahalwar et al., 2014; Moro et al., 2012; North et al., 2007). For simplicity in the text, these lines are referred to with short forms listed in square brackets: $T g(k d r l: C h e r r y-C A A X)[k d r l: m C h e r r y]$,

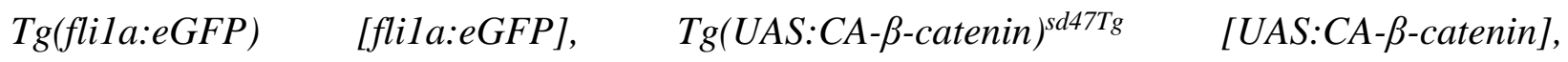
Tg(gata2b:KalTA4)[HSC:Gal4] and (UAS:Lifeact:eGFP) [UAS:eGFP], Tg(UAS:Cre) [UAS:Cre], Tg(bactin2:loxP-BFP-loxP-DsRed) [loxP BFP loxP dsRed].

MO for $f z d 9 b$ was targeted to block the ATG start codon with sequence 5'AGGTGAGCTTCCCATTCTGGATTTT -3' from GeneTools. 1-cell stage zygotes were injected 
with 2ng of $f z d 9 b \mathrm{MO}$ and disruption of protein expression was confirmed with a fluorescently tagged mRNA. Suboptimal MO dosage was $0.5 \mathrm{ng}$. The wnt $9 a$ MO has been previously described (Grainger et al., 2016b) and was used at 0.1ng. The egfra MO has been previously described (Zhao and Lin, 2013) and was used at $2.5 \mathrm{ng}$ or $1 \mathrm{ng}$. Rescue experiments were performed using $20 \mathrm{pg} f z d$ chimeric mRNA synthesized using the SP6 mMessage machine kit (Ambion) according to the manufacturer's recommendations.

CRISPR/Cas9 was used to generate germline mutants for $f z d 9 b$; $\operatorname{sgRNAs}$ were chosen according to their ability to cleave DNA in vitro as previously described (Grainger et al., 2016a). Mutation of the $f z d 9 b$ locus at the N-terminal was achieved 100ng of cas 9 mRNA (Trilink) and 100ng of sgRNA (GGCTCTTATGACCTGGAGAG) and generated mutants with either a 2bp insertion $\left(f z d 9 b^{2 b p}\right)^{\mathrm{fb} 203}$, or a $7 \mathrm{bp}$ deletion $\left(f z d 9 b^{7 b p}\right)^{\mathrm{fb} 204}$. Similarly, mutation at the C-terminal tail was achieved by injecting the sgRNA (GGACTCTTCAGTGCCCACAG). For simplicity, in the text, these are referred to as $f z d 9 b^{-/-}$and $f z d 9 b^{\triangle C T T / \triangle C T T}$, respectively. Mutations were confirmed by sequencing individuals.

$\operatorname{Tg}(f z d 9 b: G a l 4)$ founders were established by injecting 25pg of a Tol2 kit (Kwan et al., 2007) generated plasmid with 100pg of transposase mRNA at the 1-cell stage. The transgenic plasmid encoded a $4.3 \mathrm{~kb} f z d 9 b$ promoter region amplified using the primers: 5' CTCCCATGAGGCAGAACGTGTGT 3' and 5' AGTCCGCGAGCAGCTTGTCTGTT 3'; this was cloned into a p5E MCS Tol2 entry vector using XhoI and SacII restriction sites and then combined with a Gal4 middle entry and polyA 3 prime entry vector by Gateway Assembly to make a full transgene construct with cmlc2:gfp in the backbone. The resultant animals were crossed to 
$T g(U A S: Y F P)$, and expression compared to in situ hybridization for $f z d 9 b$ to identify founders that recapitulated endogenous $f z d 9 b$ expression.

Lineage tracing experiments were visualized on a Zeiss LSM 880 with Airyscan. Representative images were produced by combining 3-4 Z-slices per scan.

\section{Whole-mount in situ hybridization (WISH) and Fluorescent WISH (FISH)}

RNA probe synthesis was carried out according to the manufacturer's recommendations using the DIG-RNA labeling kit, or the fluorescein labeling kit for FISH (Roche). Probes for flila, rag1, dll4, dlc, notchlb, kdrl, cdh17, cmyb and runxl and WISH protocols have been previously described (Clements et al., 2011; Kobayashi et al., 2014; Rowlinson and Gering, 2010). The probe for $f z d 9 b$ was generated from the full-length cDNA. FISH signal was developed as previously described (Brend and Holley, 2009).

\section{Fluorescence activated cell sorting and quantitative PCR}

Zebrafish were dissociated using Liberase TM (Roche) and filtered through an 80um filter. Cells were sorted on a BD Influx cell sorter according to standard procedures. RNA and cDNA were synthesized by standard means and qPCR was performed using FastStart Universal SYBR Green Master Mix (Roche) according to the manufacturer's recommendations and analyzed using the $2^{-}$ ${ }^{\Delta \Delta \mathrm{Ct}}$ method (Schefe et al., 2006). Sequences of primers are shown in the table below.

\begin{tabular}{|c|l|l|}
\hline Target & Direction & 5' SEQUENCE 3' \\
\hline \multirow{3}{*}{ ef1a } & $\mathrm{F}$ & GGAGGCTGCCAACTTCAACGCTC \\
\cline { 2 - 3 } cmyb & $\mathrm{R}$ & GCTTCTTGCCAGAACGACGGTCG \\
\cline { 2 - 3 } & $\mathrm{F}$ & GAGGGGCAAGATCTCCACAC \\
\hline runx1 & $\mathrm{F}$ & GGACTTCCTATGGGTCTGCG \\
\hline
\end{tabular}




\begin{tabular}{|c|c|c|}
\hline & $\mathrm{R}$ & GGATCTGTGAACGCCGTCAG \\
\hline \multirow[b]{2}{*}{ gata2b } & $\mathrm{F}$ & ACCACCACACTCTGGAGAC \\
\hline & $\mathrm{R}$ & CTGTTGCGTGTCTGAATACC \\
\hline \multirow[b]{2}{*}{$C D 45$} & $\mathrm{~F}$ & CTCTACGCAAAGCTAGGCCA \\
\hline & $\mathrm{R}$ & ACTTGTCCATTCTGAGCAGG \\
\hline \multirow[b]{2}{*}{$C-M Y B$} & $\mathrm{~F}$ & GTCACAAATTGACTGTTACAACACCAT \\
\hline & $\mathrm{R}$ & TTCTACTAGATGAGAGGGTGTCTGAGG \\
\hline \multirow[b]{2}{*}{$C D 31$} & $\mathrm{~F}$ & TTCCTGACAGTCTCTTGAGTGG \\
\hline & $\mathrm{R}$ & TTTGGCTAGGCGTGGTTCTCAT \\
\hline \multirow[b]{2}{*}{$C D 34$} & $\mathrm{~F}$ & CAATGAGGCCACAACAAACATC \\
\hline & $\mathrm{R}$ & GGTGGTGAACACTGTGCTGATT \\
\hline \multirow[b]{2}{*}{$R \cup N X 1$} & $\mathrm{~F}$ & ACTCGGCTGAGCTGAGAAATG \\
\hline & $\mathrm{R}$ & GACTTGCGGTGGGTTTGTG \\
\hline \multirow[b]{2}{*}{ GAPDH } & $\mathrm{F}$ & CCTGCACCACCAACTGCTTA \\
\hline & $\mathrm{R}$ & CCATCACGCCACAGTTTCC \\
\hline
\end{tabular}

\section{Quantifying HSPCs}

HSPCs were quantified by counting the number of kdrl:mCherry; gata2b:GFP double positive cells in floor of the DA in the region above the yolk extension in a $625 \mu \mathrm{m}$ confocal Z-stack encompassing the entire mediolateral segment of the aorta. The number of HSPCs per mm was calculated from this data. Confocal images were generated by stacking 1-4 individual Z-slices. When quantifying WISH data, the number of $c m y b+$ or runx $1+$ cells were counted above the yolk extension.

\section{Human embryonic stem cell culture and HSPC differentiation}

All experiments described in this study were approved by a research oversight committee (IRB/ESCRO Protocol \#100210, PI Willert). Human embryonic stem (hES) cell H9 (WA09, NIH Registration number 062) cells were obtained from WiCell. Cells were maintained in Essential 8 (E8) media (Chen et al., 2011), with minor modifications, as previously described (Huggins et al., 2017). Plasmids encoding pools of shRNAs for FZD9 and WNT9A were obtains from ABM. The 
cell lines harboring shRNAs for control, WNT9A and FZD9 were generated by lentiviral transduction, as previously described (Moya et al., 2014). Virally-infected cells were selected with puromycin (4 ug/mL), and differentiated to HSPCs as previously described (Ng et al., 2008; $\mathrm{Ng}$ et al., 2005). Cells were dissociated and HSPCs were quantified by flow cytometry as previously described (Richter et al., 2018).

\section{APEX2-mediated proximity labeling}

Chinese hamster ovary $(\mathrm{CHO})$ cells were stably integrated with a CMV:Wnt9a construct. Conditioned medium from $\mathrm{CHO}$ cells with or without this construct was collected for two weeks, pooled together, filtered through a $0.22 \mu \mathrm{m}$ filter and tested for Wnt9a activity by luciferase STF assay with Fzd9b. HEK293T cells were stably integrated with a CMV:Fzd9b-5GS-APEX2 construct. APEX2-mediated proximity labeling was carried out essentially as described (Hung et al., 2016; Lam et al., 2015). Briefly, confluent 150mm plates of CMV:Fzd9b-5GS-APEX2 cells were treated with biotin-phenol for a total of 30 minutes each, ending at the time of hydrogen peroxide treatment. Cells were treated with Wnt9a conditioned medium for 1 or 5 minutes, or with WT CHO conditioned medium for 5 minutes. Cells were treated with hydrogen peroxide for 1 minute, quenched, lysed, and biotinylated proteins enriched by streptavidin pulldown, as previously described (Hung et al., 2016).

\section{Protein digestion}

To denature the eluted proteins, an equal volume of $8 \mathrm{M}$ Urea in $50 \mathrm{mM}$ HEPES, pH 8.5 was added to each sample. Protein disulfide bonds were reduced by Dithiothreitol (DTT, Sigma) and alkylated with Iodoacetamide (Sigma) as previously described (Haas, 2006). Proteins were 
precipitated using trichloroacetic acid and resuspended in $300 \mu \mathrm{l}$ of buffer (1 M urea (Fisher), 50 mM HEPES, $\mathrm{pH} 8.5$ ) for proteolytic digestion.

Proteins were serially digested with $30 \mu \mathrm{g}$ of LysC overnight at room temperature, then with $3 \mu \mathrm{g}$ of trypsin for 6 hours at $37^{\circ} \mathrm{C}$ (Lapek et al., 2017), quenched by the addition of trifluoracetic acid (TFA, Pierce), and peptides were desalted with C18-StageTips extraction columns (Waters) as previously described (Lapek et al., 2017). Peptides were dried in a speed vac, then re-suspended in 50\% Acetonitrile/5\% formic acid and quantified by the Pierce Quantitative Colorimetric Peptide Assay (Thermo); an equal amount of each sample to be run on a pooled bridge channel (Lapek et al., 2018). Aliquots were dried under vacuum and stored at $-80^{\circ} \mathrm{C}$ until they were labeled with Tandem Mass Tag (TMT) reagents.

\section{TMT labeling}

Peptides were labeled with 10-plex TMT reagents (Thermo) (McAlister et al., 2012; Thompson et al., 2003) as previously described (Lapek et al., 2017). Briefly, TMT reagents were reconstituted in dry acetonitrile (Sigma) at $20 \mu \mathrm{g} / \mathrm{mL}$. Dried peptides were re-suspended in $30 \%$ dry acetonitrile in $200 \mathrm{mM}$ HEPES, $\mathrm{pH} 8.5$, and $8 \mu \mathrm{L}$ of the appropriate TMT reagent was added to the peptides. Reagent 126 (Thermo) was used to bridge between mass spectrometry runs. Remaining reagents were used to label samples in a random order. Labeling was carried out for 1 hour at room temperature and was quenched by adding $9 \mu \mathrm{L}$ of $5 \%$ hydroxylamine (Sigma) which was allowed to react for 15 mins at room temperature. Labeled samples were acidified by adding $50 \mu \mathrm{L}$ of 1\% TFA, pooled into appropriate 10-plex TMT samples and desalted with C18 Sep-Paks. 


\section{LC-MS2/MS3 Analysis}

All LC-MS2/MS3 experiments were performed on an Orbitrap Fusion mass spectrometer (Thermo) with an in-line Easy-nLC 1000 (Thermo). Home-pulled, home-packed columns (100 mm ID x $30 \mathrm{~cm}, 360 \mathrm{~mm}$ OD) were used for analysis. Analytical columns were triple-packed with $5 \mu \mathrm{m} \mathrm{C} 4$ resin, $3 \mu \mathrm{m} \mathrm{C18}$ resin, and $1.8 \mu \mathrm{m} \mathrm{C18}$ resin (Sepax) to lengths of $0.5 \mathrm{~cm}, 0.5 \mathrm{~cm}$, and $30 \mathrm{~cm}$, respectively. Peptides were eluted with a linear gradient from 11 to $30 \%$ acetonitrile in $0.125 \%$ formic acid over $165 \mathrm{~min}$ at a flow rate of $300 \mathrm{~nL} /$ minute and heating the column to $60^{\circ} \mathrm{C}$. Nano-electrospray ionization was performed by applying $2000 \mathrm{~V}$ through a stainless-steel Tjunction at the inlet of the microcapillary column.

The mass spectrometer was operated in a data-dependent mode, with a survey scan performed over a mass to charge $(\mathrm{m} / \mathrm{z})$ range of $500-1200$ at a resolution of $1.2 \times 10^{5}$ in the Orbitrap. The target automatic gain control (AGC) was set to $2 \times 10^{5}$ with a maximum inject time of $100 \mathrm{~ms}$ and an slens RF of 60. Top Speed mode was used to select the most abundant ions for tandem MS analysis. All data collected was centroided.

Ions above an intensity threshold of $5 \times 10^{5}$ were isolated in the quadrupole and fragmented using collision-induced dissociation (normalized energy: 30\%) for MS2 analysis. MS2 fragments were detected in the ion trap using the rapid scan rate setting with an AGC of $1 \times 10^{4}$ and a maximum injection time of $35 \mathrm{~ms}$.

For MS3 analysis, synchronous precursor selection was used to maximize quantitation sensitivity of the TMT reporter ions (McAlister et al., 2014). Up to 10 MS2 ions were simultaneously isolated 
and fragmented with high energy collision induced dissociation (normalized energy: 50\%). MS3 fragment ions were analyzed in the Oribtrap with a resolution of $6 \times 10^{4}$. The AGC was set to $5 \mathrm{x}$ $10^{4}$ using a maximum injection time of $150 \mathrm{~ms}$. MS2 ions $40 \mathrm{~m} / \mathrm{z}$ below and $15 \mathrm{~m} / \mathrm{z}$ above the MS1 precursor ion were excluded from MS3 selection.

\section{Data Processing}

Raw spectral data were processed using Proteome Discoverer 2.1.0.81 (Thermo). MS2 spectra were identified using the Sequest HT node (Eng et al., 1994), searching against the Human Uniprot database (downloaded: 5/11/2017) with the zebrafish Fzd9b sequence appended. False discovery rate (FDR) estimation was performed using a reverse decoy database (Elias and Gygi, 2007; Elias et al., 2005; Peng et al., 2003). Search parameters were as follows. Mass tolerances were set to 50 ppm and 0.6 Da for MS1 and MS2 scans, respectively. Full trypsin digestion was specified with a maximum of two missed cleavages per peptide. Modifications included static 10-plex TMT tags on peptide n-termini and lysine, static carbamidomethylation of cysteine and variable oxidation of methionine. Data were filtered to a $1 \%$ FDR at both the peptide and protein level.

The intensities of TMT reporter ions were extracted from the MS3 scans for quantitative analysis. Prior to quantitation, spectra were filtered to have an average signal to noise of 10 across all labels and an isolation interference less than 25\%. Data were normalized in a two-step process as previously described (Lapek et al., 2018), by normalizing each protein the pooled bridge channel value and then normalizing to the median of each reporter ion channel and the entire dataset. The dataset has been uploaded to ProteomeXchange (PXD010649) through MassIVE (MSV000082677). 


\section{Statistical Analysis}

For APEX results, two-tailed student's t-tests were used to determine significantly enriched proteins at each time point. If the variances between samples were determined to be unequal by an F-test, Welch's correction was used. Significantly changing proteins were prioritized using pi score (Xiao et al., 2014), a metric that takes both p-value and fold-change into account. Gene ontology of the significant proteins was performed using the database for annotation, visualization and integrated discovery (DAVID) server (Huang da et al., 2009; Huang et al., 2007). For STF assays and qPCR or cell counting comparing more than two populations, one-way ANOVA, followed by Bonferroni post-test analysis were conducted. For qPCR or cell counting comparing only two populations, two-tailed student's t-tests were used.

\section{Plasmids}

Expression constructs were generated by standard means using PCR from cDNA libraries generated from zebrafish larvae at $24 \mathrm{hpf}$, or from hES cells; these were cloned into pCS2+, downstream of a CMV promoter, and upstream of IRES:mKate2. Addgene provided expression vectors for Cas9 (47929), guide RNAs (46759) and zebrafish ctnnbl (17199).

\section{Author Contributions}

SG conceived, designed and conducted experiments and analysis, and wrote the manuscript. NN and JR designed and conducted experiments and analysis, JS, BL, RB, CHO and JH conducted experiments and analysis, JMW, MCT and DG performed mass spectrometry and analysis, CK and ID provided zebrafish lines, DT and KW supervised experiments and edited the manuscript. 


\section{Acknowledgements}

C. Fine and J. Olvera for FACS assistance; C. Pouget and P. Sahai-Hernandez for technical assistance and critical reading of the manuscript; R. Espin-Palazon, J. Nussbacher, I.J. Huggins and N. Grimsey for critical reading of the manuscript; I.J. Huggins for antibodies; N.Gohad for microscopy assistance. SG was supported by awards from the American Heart Association (14POST18340021), the Leukemia and Lymphoma Society (5431-15) and the NIH/NHLBI (K99HL133458). Research reported in this publication was supported by the National Heart, Lung, And Blood Institute of the National Institutes of Health under Award Number K99HL133458. The content is solely the responsibility of the authors and does not necessarily represent the official views of the National Institutes of Health. JR was supported by was supported in part by the UCSD Interdisciplinary Stem Cell Training Program (CIRM TG2-01154) and by the American Heart Association Predoctoral Fellowship 16PRE27340012. This work was supported in part by funding to KW from the UCSD Stem Cell Program and was made possible in part by the CIRM Major Facilities grant (FA1-00607) to the Sanford Consortium for Regenerative Medicine. DT was supported by Scholar Award (1657-13) from The Leukemia and Lymphoma Society and CIRM (RB4-06158). DT and KW were supported in part by NIH/NHLBI under the Grant R01HL135205. JMW was supported by Graduate Training in Cellular and Molecular Pharmacology Training Grant NIH T32 GM007752. Harvard Stem Cell Institute and NIDDK grant UH2/3DK107372 to I.A.D.

\section{Conflict of Interest}

The authors do not report any conflict of interest. 


\section{Figure Legends}

Figure 1: Fzd9b interacts with Wnt9a in vitro. A. Quantification of HEK293T cell STF assay screen with zebrafish Wnt9a and Fzds. Bars represent the mean of a minimum of 3 biological replicates; error bars represent standard deviation; *** $\mathrm{P}<0.001$ compared to Wnt9a alone. B. Coculture assay set up for C. C. HEK293T cells expressing zebrafish Wnt9a were mixed with HEK293T STF cells expressing zebrafish Fzd9b or Fzd5 and assayed for Wnt activity. Bars represent the mean of a minimum of 3 biological replicates; error bars represent standard deviation; $* * * \mathrm{P}<0.001$ compared to Wnt9a cells with mock transfected HEK293T STF cells. (See also Figure S1).

Figure 2: Fzd9b is required for zebrafish hematopoietic stem cell development. A. $f z d 9 b$ is expressed in the anterior lateral plate mesoderm and neural tissues. Scale bar is 200um. B. Expression of $f z d 9 b$ in 16 hpf zebrafish embryos overlaps with flila expression in the medial lateral plate mesoderm (MLPM), the tissue from which HSPCs are derived. PLPM- posterior lateral plate mesoderm, ALPM- anterior lateral plate mesoderm. Scale bar is 10um. C. Endothelial cell emerging from the dorsal aorta is labeled by fzd9b:Gal4; UAS:GFP at 40 hpf, during the time of HSPC emergence. Scale bar is 10um. D. Cells in the thymus are labeled by fzd9b:Gal4; UAS:GFP at 6 dpf. T-thymus, OV-otic vesicle; scale bar is 25 um. E. WISH for the later HSC marker $c m y b$ at $40 \mathrm{hpf}$ in $f z d 9 b$ morphants and controls. Scale bar is 30um. F. Quantification of E. G. qPCR for the later HSC marker cmyb in $f z d 9 b$ morphants and controls at $40 \mathrm{hpf}$. Scale bar is $30 \mathrm{um}$. $\mathbf{H}$. Quantification of WISH for the later HSC marker $c m y b$ at 40 hpf in $f z d 9 b$ mutants and controls. I. qPCR for the HSC marker $c m y b$ in $f z d 9 b$ mutants and controls at 40 hpf. n.s. not significant. 
$* * * \mathrm{P}<0.001, * * * * \mathrm{P}<0.0001$ compared to control (uninjected or WT siblings). (See also Figure $\mathrm{S} 2)$.

Figure 3: Fzd9b interacts genetically with Wnt9a. A-D. WISH for the HSC marker $c m y b$ at 40 hpf in WT (A, B), UAS:CA- $\beta$-catenin (C) and gata2b:Gal4;UAS:CA- $\beta$-catenin (D), injected with $f z d 9 b$ morpholino (B-D). Scale bar is 30um. E. Quantification of A-D. F. LRP6 immunoblot of lysates from WT HEK293T STF cells (WT parental), CRISPR-treated cells without disruption of LRP6 (CRISPR WT), and LRP6 null mutant line (LRP6 KO). G. Wnt reporter induction in WT and LRP6 KO HEK293T STF cells transfected with Wnt9a and Fzd9b. H-K. WISH for the HSC marker cmyb at $40 \mathrm{hpf}$ in $w n t 9 a(\mathbf{J}, \mathbf{K})$ and $f z d 9 b$ (I, K) low dose MO injected fish and sibling controls $(\mathbf{H})$. Scale bar is 30um. L. Quantification of H-K. n.s. not significant. $* * * \mathrm{P}<0.001$ compared to WT controls. (See also Figure S3).

Figure 4: WNT9A and FZD9 are required for human hematopoiesis in vitro. A. Quantification of HEK293T cell STF assay screen with human WNT9A and FZDs. Bars represent the mean of a minimum of 3 biological replicates; error bars represent standard deviation; $* \mathrm{P}<0.05$, $* * \mathrm{P}>0.001, * * * * \mathrm{P}<0.0001$ compared to WNT9A alone (mock). B. Schematic of experimental design for HSPC derivation. Representative flow cytometry plots of CD34 vs CD45 cells after 14 days of differentiation towards HSPCs in shControl (C), shWNT9A (D) and shFZD9 (E) transduced cells. Note the loss of double positive cells with the loss of WNT9A or FZD9. F. Quantification CD34/CD45 double positive cells. Bars represent the mean from a minimum of 6 
biological replicates from 2 independent experiments from $\mathbf{C}$-E. $* \mathrm{P}<0.05, * * * \mathrm{P}<0.001$ compared to shControl cells. (See also Figure S4).

Figure 5: Wnt9a-Fzd9b specificity is mediated intracellularly. A. Quantification of HEK293T cell STF assay with zebrafish Wnt9a and Fzd9b with and without the cysteine rich domain (CRD). B. Quantification of HEK293T cell STF assay with zebrafish Wnt9a and Fzd9b/Fzd8a chimeras. Schematic representations of the constructs used are shown on the $\mathrm{x}$-axis. Red represents coding regions from $f z d 8 a$; green represents coding regions from $f z d 9 b$. Bars represent the mean of a minimum of 3 biological replicates; error bars represent standard deviation; $* * * \mathrm{P}<0.001$ compared to Wnt9a with WT Fzd9b. C-F. WISH for the HSC marker $c m y b$ at 40 hpf in $f z d 9 b$ morphants (D-G) injected with mRNAs for $f z d 9 b(\mathbf{E}), f z d 8 a(\mathbf{F})$ and $f z d 8 a$ with ICL3 and CTT from $f z d 9 b$ (G) and uninjected control (D). Scale bar is 30um. H. Quantification of D-G. n.s. = not significant. $* * * \mathrm{P}<0.001$ compared to WT controls. (See also Figure S5).

Figure 6: EGFR mediates Wnt9a-Fzd9b signaling. A-H. Non-permeabilized immunofluorescence for Wnt9a in Fzd9b cells treated as shown. Scale bar is 15 um. I. Quantification of HEK293T cell STF assay with zebrafish Wnt9a and Fzd9b treated with the EGFR blocking antibody Cetuximab. J. Quantification of HEK293T cell STF assay with zebrafish Wnt9a and Fzd9b treated with control or EGFR siRNAs. K. Quantification of STF assay with human WNT9A CHO cells co-cultured with stably transfected FZD9 HEK293T STF cells treated with control or EGFR siRNAs. L. WISH for the later HSC marker cmyb at 40 hpf in egfra morphants and controls. Scale bar is 30um. M. Quantification of L. N. qPCR for the HSC markers 
runxl and gata $2 b$ in egfra morphants and controls at $40 \mathrm{hpf}$. O. Quantification of WISH for $c m y b$ at $40 \mathrm{hpf}$ in fish injected with suboptimal MO dosages. P. Heatmap of Fzd9b-APEX2 proximity labeled normalized intensities of RAB members in the early endosome, late endosome and recycling endosome over time. Q. Heatmap of Fzd9b-APEX2 proximity labeled normalized intensities of AP-2 members, as well as associated machinery. Quantification of STF assay with zebrafish Wnt9a and Fzd9b (R) or human WNT9A and FZD9 (S), cultured with concentrations of chlorpromazine $(\mathrm{CPZ})$ as shown. In all figures, bars represent the mean of a minimum of 3 biological replicates; error bars represent standard deviation; $* \mathrm{P}<0.05, * * \mathrm{P}<0.01, * * * * \mathrm{P}<0.0001$ compared to controls. (See also Figure S6).

Figure 7: Fzd9b Tyrosine phosphorylation is required for Wnt9a-Fzd9b signaling. A. Schematic of Fzd9b protein with putative EGFR tyrosine phosphorylation sites. B. Western blot for Fzd9b in phosphotyrosine immunoprecipitations from WT or HEK293T cells stably transfected with Fzd9b-mKate and treated for 1 minute with either WT CHO conditioned medium, or Wnt9aexpressing $\mathrm{CHO}$ conditioned medium as shown. Note the increase in phosphotyrosine Fzd9b (2.98 vs 1, arbitrary units). C. Quantification of HEK293T cell STF assay with zebrafish Fzd9b point mutants. Bars represent the mean of a minimum of 3 biological replicates; error bars represent standard deviation; $* * * * \mathrm{P}<0.0001$ compared to controls. D. Model of Fzd9b signaling specificity with Wnt9a. i. Fzd9b, LRP6 and EGFR are resident in proximity at the cell surface; ii. the destruction complex targets $\beta$-catenin for degradation in the absence of a ligand; iii. in the presence of Wnt9a, EGFR phosphorylates the Fzd9b tail at Y556 and Y571. iv. AP-2 and clathrin are recruited. v. Fzd9b-LRP6 oligomerization leads to dissociation of the destruction complex and 
bioRxiv preprint doi: https://doi.org/10.1101/387043; this version posted August 7, 2018. The copyright holder for this preprint (which was not certified by peer review) is the author/funder. All rights reserved. No reuse allowed without permission.

Grainger, et al, 2018

release of $\beta$-catenin into the cytosol, allowing for nuclear translocation. vi. Nuclear $\beta$-catenin transactivates a program for HSC proliferation. (See also Figure S7). 


\section{References}

Ablain, J., and Zon, L.I. (2016). Tissue-specific gene targeting using CRISPR/Cas9. Methods Cell Biol 135, 189-202.

Ahumada, A., Slusarski, D.C., Liu, X., Moon, R.T., Malbon, C.C., and Wang, H.Y. (2002). Signaling of rat Frizzled-2 through phosphodiesterase and cyclic GMP. Science 298, 2006-2010. Baba, Y., Yokota, T., Spits, H., Garrett, K.P., Hayashi, S.-I., and Kincade, P.W. (2006). Constitutively active beta-catenin promotes expansion of multipotent hematopoietic progenitors in culture. Journal of Immunology (Baltimore, Md: 1950) 177, 2294-2303.

Baig-Lewis, S., Peterson-Nedry, W., and Wehrli, M. (2007). Wingless/Wnt signal transduction requires distinct initiation and amplification steps that both depend on Arrow/LRP. Dev Biol 306, 94-111.

Batta, K., Florkowska, M., Kouskoff, V., and Lacaud, G. (2014). Direct reprogramming of murine fibroblasts to hematopoietic progenitor cells. Cell Rep 9, 1871-1884.

Bertrand, J.Y., Chi, N.C., Santoso, B., Teng, S., Stainier, D.Y., and Traver, D. (2010). Haematopoietic stem cells derive directly from aortic endothelium during development. Nature 464, 108-111.

Bertrand, J.Y., Kim, A.D., Teng, S., and Traver, D. (2008). CD41+ cmyb+ precursors colonize the zebrafish pronephros by a novel migration route to initiate adult hematopoiesis. Development 135, 1853-1862.

Blitzer, J.T., and Nusse, R. (2006). A critical role for endocytosis in Wnt signaling. BMC Cell Biol 7, 28.

Blom, N., Gammeltoft, S., and Brunak, S. (1999). Sequence and structure-based prediction of eukaryotic protein phosphorylation sites. J Mol Biol 294, 1351-1362.

Bouldin, C.M., and Kimelman, D. (2014). Dual fucci: a new transgenic line for studying the cell cycle from embryos to adults. Zebrafish 11, 182-183.

Brend, T., and Holley, S.A. (2009). Zebrafish whole mount high-resolution double fluorescent in situ hybridization. J Vis Exp.

Brown, L.A., Rodaway, A.R., Schilling, T.F., Jowett, T., Ingham, P.W., Patient, R.K., and Sharrocks, A.D. (2000). Insights into early vasculogenesis revealed by expression of the ETSdomain transcription factor Fli-1 in wild-type and mutant zebrafish embryos. Mech Dev 90, 237252.

Buchtova, M., Oralova, V., Aklian, A., Masek, J., Vesela, I., Ouyang, Z., Obadalova, T., Konecna, Z., Spoustova, T., Pospisilova, T., et al. (2015). Fibroblast growth factor and canonical WNT/beta-catenin signaling cooperate in suppression of chondrocyte differentiation in experimental models of FGFR signaling in cartilage. Biochim Biophys Acta 1852, 839-850. Burns, C.E., Traver, D., Mayhall, E., Shepard, J.L., and Zon, L.I. (2005). Hematopoietic stem cell fate is established by the Notch-Runx pathway. Genes \& Development 19, 2331-2342. Butko, E., Distel, M., Pouget, C., Weijts, B., Kobayashi, I., Ng, K., Mosimann, C., Poulain, F.E., McPherson, A., Ni, C.-W., et al. (2015). Gata2b is a restricted early regulator of hemogenic endothelium in the zebrafish embryo. Development 142, 1050-1061.

Canals, M., Scholten, D.J., de Munnik, S., Han, M.K., Smit, M.J., and Leurs, R. (2012). Ubiquitination of CXCR7 controls receptor trafficking. PLoS One 7, e34192.

Cardone, L., Bardelli, A., and Avvedimento, V.E. (2012). Activation of beta-catenin by oncogenic PIK3CA and EGFR promotes resistance to glucose deprivation by inducing a strong antioxidant response. PLoS One 7, e37526. 
Chan, K.K., and Lo, R.C. (2018). Deregulation of Frizzled Receptors in Hepatocellular Carcinoma. Int J Mol Sci 19.

Chen, G., Gulbranson, D.R., Hou, Z., Bolin, J.M., Ruotti, V., Probasco, M.D., Smuga-Otto, K., Howden, S.E., Diol, N.R., Propson, N.E., et al. (2011). Chemically defined conditions for human iPSC derivation and culture. Nat Methods 8, 424-429.

Cho, C., Smallwood, P.M., and Nathans, J. (2017). Reck and Gpr124 Are Essential Receptor Cofactors for Wnt7a/Wnt7b-Specific Signaling in Mammalian CNS Angiogenesis and BloodBrain Barrier Regulation. Neuron 95, 1221-1225.

Civenni, G., Holbro, T., and Hynes, N.E. (2003). Wnt1 and Wnt5a induce cyclin D1 expression through ErbB1 transactivation in HC11 mammary epithelial cells. EMBO Rep 4, 166-171.

Clements, W.K., Kim, A.D., Ong, K.G., Moore, J.C., Lawson, N.D., and Traver, D. (2011). A somitic Wnt16/Notch pathway specifies haematopoietic stem cells. Nature 474, 220-224.

Clements, W.K., and Traver, D. (2013). Signalling pathways that control vertebrate haematopoietic stem cell specification. Nature Reviews Immunology 13, 336-348.

Clevers, H., and Nusse, R. (2012). Wnt/beta-Catenin Signaling and Disease. Cell 149, 11921205.

Cong, F., Schweizer, L., and Varmus, H. (2004). Wnt signals across the plasma membrane to activate the beta-catenin pathway by forming oligomers containing its receptors, Frizzled and LRP. Development 131, 5103-5115.

Cooper, S., Bennett, W., Andrade, J., Reubinoff, B.E., Thomson, J., and Pera, M.F. (2002). Biochemical properties of a keratan sulphate/chondroitin sulphate proteoglycan expressed in primate pluripotent stem cells. J Anat 200, 259-265.

Cumano, A., Ferraz, J.C., Klaine, M., Di Santo, J.P., and Godin, I. (2001). Intraembryonic, but not yolk sac hematopoietic precursors, isolated before circulation, provide long-term multilineage reconstitution. Immunity 15, 477.

Damm, E.W., and Clements, W.K. (2017). Pdgf signalling guides neural crest contribution to the haematopoietic stem cell specification niche. Nat Cell Biol 19, 457-467.

Daub, H., Wallasch, C., Lankenau, A., Herrlich, A., and Ullrich, A. (1997). Signal characteristics of $\mathrm{G}$ protein-transactivated EGF receptor. EMBO J 16, 7032-7044.

Dege, C., and Sturgeon, C.M. (2017). Directed Differentiation of Primitive and Definitive Hematopoietic Progenitors from Human Pluripotent Stem Cells. J Vis Exp.

Del Vecchio, C.A., Jensen, K.C., Nitta, R.T., Shain, A.H., Giacomini, C.P., and Wong, A.J. (2012). Epidermal growth factor receptor variant III contributes to cancer stem cell phenotypes in invasive breast carcinoma. Cancer Res 72, 2657-2671.

Detrich, H.W., 3rd, Kieran, M.W., Chan, F.Y., Barone, L.M., Yee, K., Rundstadler, J.A., Pratt, S., Ransom, D., and Zon, L.I. (1995). Intraembryonic hematopoietic cell migration during vertebrate development. Proc Natl Acad Sci U S A 92, 10713-10717.

Dijksterhuis, J.P., Baljinnyam, B., Stanger, K., Sercan, H.O., Ji, Y., Andres, O., Rubin, J.S., Hannoush, R.N., and Schulte, G. (2015). Systematic mapping of WNT-FZD protein interactions reveals functional selectivity by distinct WNT-FZD pairs. J Biol Chem 290, 6789-6798.

Dijksterhuis, J.P., Petersen, J., and Schulte, G. (2014). WNT/Frizzled signalling: receptor-ligand selectivity with focus on FZD-G protein signalling and its physiological relevance: IUPHAR Review 3. Br J Pharmacol 171, 1195-1209.

Ditadi, A., and Sturgeon, C.M. (2016). Directed differentiation of definitive hemogenic endothelium and hematopoietic progenitors from human pluripotent stem cells. Methods 101, 65-72. 
Djiane, A., Yogev, S., and Mlodzik, M. (2005). The apical determinants aPKC and dPatj regulate Frizzled-dependent planar cell polarity in the Drosophila eye. Cell 121, 621-631.

Doan, P.L., Himburg, H.A., Helms, K., Russell, J.L., Fixsen, E., Quarmyne, M., Harris, J.R., Deoliviera, D., Sullivan, J.M., Chao, N.J., et al. (2013). Epidermal growth factor regulates hematopoietic regeneration after radiation injury. Nat Med 19, 295-304.

Doody, J.F., Wang, Y., Patel, S.N., Joynes, C., Lee, S.P., Gerlak, J., Rolser, R.L., Li, Y., Steiner, P., Bassi, R., et al. (2007). Inhibitory activity of cetuximab on epidermal growth factor receptor mutations in non small cell lung cancers. Mol Cancer Ther 6, 2642-2651.

Doulatov, S., Vo, L.T., Chou, S.S., Kim, P.G., Arora, N., Li, H., Hadland, B.K., Bernstein, I.D., Collins, J.J., Zon, L.I., et al. (2013). Induction of multipotential hematopoietic progenitors from human pluripotent stem cells via respecification of lineage-restricted precursors. Cell Stem Cell $13,459-470$.

Elcheva, I., Brok-Volchanskaya, V., Kumar, A., Liu, P., Lee, J.H., Tong, L., Vodyanik, M., Swanson, S., Stewart, R., Kyba, M., et al. (2014). Direct induction of haematoendothelial programs in human pluripotent stem cells by transcriptional regulators. Nat Commun 5, 4372. Elias, J.E., and Gygi, S.P. (2007). Target-decoy search strategy for increased confidence in largescale protein identifications by mass spectrometry. Nat Methods 4, 207-214.

Elias, J.E., Haas, W., Faherty, B.K., and Gygi, S.P. (2005). Comparative evaluation of mass spectrometry platforms used in large-scale proteomics investigations. Nat Methods 2, 667-675. Eng, J.K., McCormack, A.L., and Yates, J.R. (1994). An approach to correlate tandem mass spectral data of peptides with amino acid sequences in a protein database. J Am Soc Mass Spectrom 5, 976-989. Espin-Palazon, R., Stachura, D.L., Campbell, C.A., Garcia-Moreno, D., Del Cid, N., Kim, A.D., Candel, S., Meseguer, J., Mulero, V., and Traver, D. (2014). Proinflammatory signaling regulates hematopoietic stem cell emergence. Cell 159, 1070-1085.

Eubelen, M., Bostaille, N., Cabochette, P., Gauquier, A., Tebabi, P., Dumitru, A.C., Koehler, M., Gut, P., Alsteens, D., Stainier, D.Y.R., et al. (2018). A molecular mechanism for Wnt ligandspecific signaling. Science.

Farin, H.F., Jordens, I., Mosa, M.H., Basak, O., Korving, J., Tauriello, D.V., de Punder, K., Angers, S., Peters, P.J., Maurice, M.M., et al. (2016). Visualization of a short-range Wnt gradient in the intestinal stem-cell niche. Nature 530, 340-343.

Fernandez, A., Huggins, I.J., Perna, L., Brafman, D., Lu, D., Yao, S., Gaasterland, T., Carson, D.A., and Willert, K. (2014). The WNT receptor FZD7 is required for maintenance of the pluripotent state in human embryonic stem cells. Proceedings of the National Academy of Sciences 111, 1409-1414.

Fleming, H.E., Janzen, V., Lo Celso, C., Guo, J., Leahy, K.M., Kronenberg, H.M., and Scadden, D.T. (2008). Wnt Signaling in the Niche Enforces Hematopoietic Stem Cell Quiescence and Is Necessary to Preserve Self-Renewal In Vivo. Cell Stem Cell 2, 274-283.

Fouquet, B., Weinstein, B.M., Serluca, F.C., and Fishman, M.C. (1997). Vessel patterning in the embryo of the zebrafish: guidance by notochord. Dev Biol 183, 37-48.

Georgopoulos, N.T., Kirkwood, L.A., and Southgate, J. (2014). A novel bidirectional positivefeedback loop between Wnt-beta-catenin and EGFR-ERK plays a role in context-specific modulation of epithelial tissue regeneration. J Cell Sci 127, 2967-2982. Goessling, W., North, T.E., Loewer, S., Lord, A.M., Lee, S., Stoick-Cooper, C.L., Weidinger, G., Puder, M., Daley, G.Q., Moon, R.T., et al. (2009). Genetic Interaction of PGE2 and Wnt 
Signaling Regulates Developmental Specification of Stem Cells and Regeneration. Cell 136, 1136-1147.

Goishi, K., Lee, P., Davidson, A.J., Nishi, E., Zon, L.I., and Klagsbrun, M. (2003). Inhibition of zebrafish epidermal growth factor receptor activity results in cardiovascular defects. Mech Dev 120, 811-822.

Grainger, S., Lonquich, B., Oon, C.H., Nguyen, N., Willert, K., and Traver, D. (2016a). CRISPR Guide RNA Validation In Vitro. Zebrafish.

Grainger, S., Richter, J., Palazon, R.E., Pouget, C., Lonquich, B., Wirth, S., Grassme, K.S., Herzog, W., Swift, M.R., Weinstein, B.M., et al. (2016b). Wnt9a Is Required for the Aortic Amplification of Nascent Hematopoietic Stem Cells. Cell Rep 17, 1595-1606.

Gschwind, A., Zwick, E., Prenzel, N., Leserer, M., and Ullrich, A. (2001). Cell communication networks: epidermal growth factor receptor transactivation as the paradigm for interreceptor signal transmission. Oncogene 20, 1594-1600.

Haas, J.P. (2006). Measurement of infection control department performance: state of the science. Am J Infect Control 34, 543-549.

Halleskog, C., Dijksterhuis, J.P., Kilander, M.B., Becerril-Ortega, J., Villaescusa, J.C., Lindgren, E., Arenas, E., and Schulte, G. (2012). Heterotrimeric G protein-dependent WNT-5A signaling to ERK1/2 mediates distinct aspects of microglia proinflammatory transformation. $\mathrm{J}$

Neuroinflammation 9, 111.

Herbert, S.P., Huisken, J., Kim, T.N., Feldman, M.E., Houseman, B.T., Wang, R.A., Shokat, K.M., and Stainier, D.Y. (2009). Arterial-venous segregation by selective cell sprouting: an alternative mode of blood vessel formation. Science 326, 294-298.

Holz, A., Bossinger, B., Strasser, T., Janning, W., and Klapper, R. (2003). The two origins of hemocytes in Drosophila. Development 130, 4955-4962.

Hsieh, J.C., Rattner, A., Smallwood, P.M., and Nathans, J. (1999). Biochemical characterization of Wnt-frizzled interactions using a soluble, biologically active vertebrate Wnt protein. Proc Natl Acad Sci U S A 96, 3546-3551.

Huang da, W., Sherman, B.T., and Lempicki, R.A. (2009). Systematic and integrative analysis of large gene lists using DAVID bioinformatics resources. Nat Protoc 4, 44-57.

Huang, D.W., Sherman, B.T., Tan, Q., Collins, J.R., Alvord, W.G., Roayaei, J., Stephens, R., Baseler, M.W., Lane, H.C., and Lempicki, R.A. (2007). The DAVID Gene Functional Classification Tool: a novel biological module-centric algorithm to functionally analyze large gene lists. Genome Biol 8, R183.

Huggins, I.J., Bos, T., Gaylord, O., Jessen, C., Lonquich, B., Puranen, A., Richter, J., Rossdam, C., Brafman, D., Gaasterland, T., et al. (2017). The WNT target SP5 negatively regulates WNT transcriptional programs in human pluripotent stem cells. Nature Communications 8, 1034. Hung, V., Udeshi, N.D., Lam, S.S., Loh, K.H., Cox, K.J., Pedram, K., Carr, S.A., and Ting, A.Y. (2016). Spatially resolved proteomic mapping in living cells with the engineered peroxidase APEX2. Nat Protoc 11, 456-475.

Ikeya, M., Lee, S.M., Johnson, J.E., McMahon, A.P., and Takada, S. (1997). Wnt signalling required for expansion of neural crest and CNS progenitors. Nature 389, 966-970.

Ikeya, M., and Takada, S. (1998). Wnt signaling from the dorsal neural tube is required for the formation of the medial dermomyotome. Development 125, 4969-4976.

Jaffredo, T., Gautier, R., Eichmann, A., and Dieterlen-Livre, F. (1998). Intraaortic hemopoietic cells are derived from endothelial cells during ontogeny. Development 125, 4575. 
Jagannathan-Bogdan, M., and Zon, L.I. (2013). Hematopoiesis. Development (Cambridge, England) 140, 2463-2467.

Janda, C.Y., Waghray, D., Levin, A.M., Thomas, C., and Garcia, K.C. (2012). Structural Basis of Wnt Recognition by Frizzled. Science.

Jao, L.E., Wente, S.R., and Chen, W. (2013). Efficient multiplex biallelic zebrafish genome editing using a CRISPR nuclease system. Proc Natl Acad Sci U S A 110, 13904-13909.

Jean-Charles, P.Y., Snyder, J.C., and Shenoy, S.K. (2016). Chapter One - Ubiquitination and Deubiquitination of G Protein-Coupled Receptors. Prog Mol Biol Transl Sci 141, 1-55. Ji, H., Wang, J., Nika, H., Hawke, D., Keezer, S., Ge, Q., Fang, B., Fang, X., Fang, D., Litchfield, D.W., et al. (2009). EGF-induced ERK activation promotes CK2-mediated disassociation of alpha-Catenin from beta-Catenin and transactivation of beta-Catenin. Mol Cell 36, 547-559.

Jiang, Y., Dunbar, A., Gondek, L.P., Mohan, S., Rataul, M., O'Keefe, C., Sekeres, M., Saunthararajah, Y., and Maciejewski, J.P. (2009). Aberrant DNA methylation is a dominant mechanism in MDS progression to AML. Blood 113, 1315-1325.

Jin, S.W., Beis, D., Mitchell, T., Chen, J.N., and Stainier, D.Y. (2005). Cellular and molecular analyses of vascular tube and lumen formation in zebrafish. Development 132, 5199-5209.

Katanaev, V.L. (2010). The Wnt/Frizzled GPCR signaling pathway. Biochemistry (Mosc) 75, 1428-1434.

Katanaev, V.L., Ponzielli, R., Semeriva, M., and Tomlinson, A. (2005). Trimeric G proteindependent frizzled signaling in Drosophila. Cell 120, 111-122.

Kilander, M.B., Dahlstrom, J., and Schulte, G. (2014a). Assessment of Frizzled 6 membrane mobility by FRAP supports G protein coupling and reveals WNT-Frizzled selectivity. Cell Signal 26, 1943-1949.

Kilander, M.B., Dijksterhuis, J.P., Ganji, R.S., Bryja, V., and Schulte, G. (2011a). WNT-5A stimulates the GDP/GTP exchange at pertussis toxin-sensitive heterotrimeric G proteins. Cell Signal 23, 550-554.

Kilander, M.B., Halleskog, C., and Schulte, G. (2011b). Recombinant WNTs differentially activate beta-catenin-dependent and -independent signalling in mouse microglia-like cells. Acta Physiol (Oxf) 203, 363-372.

Kilander, M.B., Petersen, J., Andressen, K.W., Ganji, R.S., Levy, F.O., Schuster, J., Dahl, N., Bryja, V., and Schulte, G. (2014b). Disheveled regulates precoupling of heterotrimeric G proteins to Frizzled 6. FASEB J 28, 2293-2305.

Kirstetter, P., Anderson, K., Porse, B.T., Jacobsen, S.E., and Nerlov, C. (2006). Activation of the canonical Wnt pathway leads to loss of hematopoietic stem cell repopulation and multilineage differentiation block. Nat Immunol 7, 1048-1056.

Kissa, K., and Herbomel, P. (2010). Blood stem cells emerge from aortic endothelium by a novel type of cell transition. Nature 464, 112-115.

Kobayashi, C., Saito, Y., Ogawa, K., and Agata, K. (2007). Wnt signaling is required for anteroposterior patterning of the planarian brain. Dev Biol 306, 714-724.

Kobayashi, I., Kobayashi-Sun, J., Kim, A.D., Pouget, C., Fujita, N., Suda, T., and Traver, D. (2014). Jam1a-Jam2a interactions regulate haematopoietic stem cell fate through Notch signalling. Nature 512, 319-323.

Korinek, V., Barker, N., Moerer, P., van Donselaar, E., Huls, G., Peters, P.J., and Clevers, H. (1998). Depletion of epithelial stem-cell compartments in the small intestine of mice lacking Tcf4. Nat Genet 19, 379-383. 
Kose, M. (2017). GPCRs and EGFR - Cross-talk of membrane receptors in cancer. Bioorg Med Chem Lett 27, 3611-3620.

Krejci, P., Aklian, A., Kaucka, M., Sevcikova, E., Prochazkova, J., Masek, J.K., Mikolka, P., Pospisilova, T., Spoustova, T., Weis, M., et al. (2012). Receptor tyrosine kinases activate canonical WNT/beta-catenin signaling via MAP kinase/LRP6 pathway and direct beta-catenin phosphorylation. PLoS One 7, e35826.

Kue, P.F., Taub, J.S., Harrington, L.B., Polakiewicz, R.D., Ullrich, A., and Daaka, Y. (2002). Lysophosphatidic acid-regulated mitogenic ERK signaling in androgen-insensitive prostate cancer PC-3 cells. Int J Cancer 102, 572-579.

Kwan, K.M., Fujimoto, E., Grabher, C., Mangum, B.D., Hardy, M.E., Campbell, D.S., Parant, J.M., Yost, H.J., Kanki, J.P., and Chien, C.B. (2007). The Tol2kit: a multisite gateway-based construction kit for Tol2 transposon transgenesis constructs. Dev Dyn 236, 3088-3099.

Lai, M.B., Zhang, C., Shi, J., Johnson, V., Khandan, L., McVey, J., Klymkowsky, M.W., Chen, Z., and Junge, H.J. (2017). TSPAN12 Is a Norrin Co-receptor that Amplifies Frizzled4 Ligand Selectivity and Signaling. Cell Rep 19, 2809-2822.

Lam, S.S., Martell, J.D., Kamer, K.J., Deerinck, T.J., Ellisman, M.H., Mootha, V.K., and Ting, A.Y. (2015). Directed evolution of APEX2 for electron microscopy and proximity labeling. Nat Methods 12, 51-54.

Lapek, J.D., Jr., Lewinski, M.K., Wozniak, J.M., Guatelli, J., and Gonzalez, D.J. (2017). Quantitative Temporal Viromics of an Inducible HIV-1 Model Yields Insight to Global Host Targets and Phospho-Dynamics Associated with Protein Vpr. Mol Cell Proteomics 16, 14471461.

Lapek, J.D., Jr., Mills, R.H., Wozniak, J.M., Campeau, A., Fang, R.H., Wei, X., van de Groep, K., Perez-Lopez, A., van Sorge, N.M., Raffatellu, M., et al. (2018). Defining Host Responses during Systemic Bacterial Infection through Construction of a Murine Organ Proteome Atlas. Cell Syst 6, 579-592 e574.

Lawson, N.D., and Weinstein, B.M. (2002). In Vivo Imaging of Embryonic Vascular Development Using Transgenic Zebrafish. Developmental Biology 248, 307-318.

Lee, F.S., Lane, T.F., Kuo, A., Shackleford, G.M., and Leder, P. (1995). Insertional mutagenesis identifies a member of the Wnt gene family as a candidate oncogene in the mammary epithelium of int-2/Fgf-3 transgenic mice. Proc Natl Acad Sci U S A 92, 2268-2272.

Leung, A., Ciau-Uitz, A., Pinheiro, P., Monteiro, R., Zuo, J., Vyas, P., Patient, R., and Porcher, C. (2013). Uncoupling VEGFA functions in arteriogenesis and hematopoietic stem cell specification. Dev Cell 24, 144-158.

Lewis, J.L., Bonner, J., Modrell, M., Ragland, J.W., Moon, R.T., Dorsky, R.I., and Raible, D.W. (2004). Reiterated Wnt signaling during zebrafish neural crest development. Development 131, 1299-1308.

Li, J., Hassan, G.S., Williams, T.M., Minetti, C., Pestell, R.G., Tanowitz, H.B., Frank, P.G., Sotgia, F., and Lisanti, M.P. (2005). Loss of caveolin-1 causes the hyper-proliferation of intestinal crypt stem cells, with increased sensitivity to whole body gamma-radiation. Cell Cycle 4, 1817-1825.

Liao, W., Bisgrove, B.W., Sawyer, H., Hug, B., Bell, B., Peters, K., Grunwald, D.J., and Stainier, D.Y. (1997). The zebrafish gene cloche acts upstream of a flk-1 homologue to regulate endothelial cell differentiation. Development 124, 381-389. 
Lis, R., Karrasch, C.C., Poulos, M.G., Kunar, B., Redmond, D., Duran, J.G.B., Badwe, C.R., Schachterle, W., Ginsberg, M., Xiang, J., et al. (2017). Conversion of adult endothelium to immunocompetent haematopoietic stem cells. Nature 545, 439-445.

Liu, T., DeCostanzo, A.J., Liu, X., Wang, H., Hallagan, S., Moon, R.T., and Malbon, C.C. (2001). G protein signaling from activated rat frizzled-1 to the beta-catenin-Lef-Tcf pathway. Science 292, 1718-1722.

Liu, X., Liu, T., Slusarski, D.C., Yang-Snyder, J., Malbon, C.C., Moon, R.T., and Wang, H. (1999). Activation of a frizzled-2/beta-adrenergic receptor chimera promotes Wnt signaling and differentiation of mouse F9 teratocarcinoma cells via Galphao and Galphat. Proc Natl Acad Sci U S A 96, 14383-14388.

Loh, K.M., van Amerongen, R., and Nusse, R. (2016). Generating Cellular Diversity and Spatial Form: Wnt Signaling and the Evolution of Multicellular Animals. Dev Cell 38, 643-655.

Luis, T.C., Ichii, M., Brugman, M.H., Kincade, P., and Staal, F.J. (2012). Wnt signaling strength regulates normal hematopoiesis and its deregulation is involved in leukemia development. Leukemia 26, 414-421.

Luis, T.C., Naber, B.A.E., Roozen, P.P.C., Brugman, M.H., de Haas, E.F.E., Ghazvini, M., Fibbe, W.E., van Dongen, J.J.M., Fodde, R., and Staal, F.J.T. (2011). Canonical wnt signaling regulates hematopoiesis in a dosage-dependent fashion. Cell stem cell 9, 345-356.

Luis, T.C., Weerkamp, F., Naber, B.A.E., Baert, M.R.M., de Haas, E.F.E., Nikolic, T., Heuvelmans, S., De Krijger, R.R., van Dongen, J.J.M., and Staal, F.J.T. (2009). Wnt3a deficiency irreversibly impairs hematopoietic stem cell self-renewal and leads to defects in progenitor cell differentiation. Blood 113, 546-554.

MacArthur, C.A., Shankar, D.B., and Shackleford, G.M. (1995). Fgf-8, activated by proviral insertion, cooperates with the Wnt-1 transgene in murine mammary tumorigenesis. J Virol 69 , 2501-2507.

MacDonald, B.T., and He, X. (2012). Frizzled and LRP5/6 receptors for Wnt/beta-catenin signaling. Cold Spring Harb Perspect Biol 4.

Maeno, M., Tochinai, S., and Katagiri, C. (1985). Differential participation of ventral and dorsolateral mesoderms in the hemopoiesis of Xenopus, as revealed in diploid-triploid or interspecific chimeras. Dev Biol 110, 503-508.

Mahalwar, P., Walderich, B., Singh, A.P., and Nusslein-Volhard, C. (2014). Local reorganization of xanthophores fine-tunes and colors the striped pattern of zebrafish. Science 345, 1362-1364. Malhotra, S., Baba, Y., Garrett, K.P., Staal, F.J., Gerstein, R., and Kincade, P.W. (2008). Contrasting responses of lymphoid progenitors to canonical and noncanonical Wnt signals. $\mathrm{J}$ Immunol 181, 3955-3964.

Mallo, M. (2016). Revisiting the involvement of signaling gradients in somitogenesis. FEBS J 283, 1430-1437.

Martin-Subero, J.I., Ammerpohl, O., Bibikova, M., Wickham-Garcia, E., Agirre, X., Alvarez, S., Bruggemann, M., Bug, S., Calasanz, M.J., Deckert, M., et al. (2009). A comprehensive microarray-based DNA methylation study of 367 hematological neoplasms. PLoS One 4, e6986. Maurel-Zaffran, C., Pradel, J., and Graba, Y. (2010). Reiterative use of signalling pathways controls multiple cellular events during Drosophila posterior spiracle organogenesis. Dev Biol 343, 18-27.

McAlister, G.C., Huttlin, E.L., Haas, W., Ting, L., Jedrychowski, M.P., Rogers, J.C., Kuhn, K., Pike, I., Grothe, R.A., Blethrow, J.D., et al. (2012). Increasing the multiplexing capacity of TMTs using reporter ion isotopologues with isobaric masses. Anal Chem 84, 7469-7478. 
McAlister, G.C., Nusinow, D.P., Jedrychowski, M.P., Wuhr, M., Huttlin, E.L., Erickson, B.K., Rad, R., Haas, W., and Gygi, S.P. (2014). MultiNotch MS3 enables accurate, sensitive, and multiplexed detection of differential expression across cancer cell line proteomes. Anal Chem $86,7150-7158$.

Medvinsky, A., and Dzierzak, E. (1996). Definitive hematopoiesis is autonomously initiated by the AGM region. Cell 86, 897.

Mishra, R., Hanker, A.B., and Garrett, J.T. (2017). Genomic alterations of ERBB receptors in cancer: clinical implications. Oncotarget 8, 114371-114392.

Moro, E., Ozhan-Kizil, G., Mongera, A., Beis, D., Wierzbicki, C., Young, R.M., Bournele, D., Domenichini, A., Valdivia, L.E., Lum, L., et al. (2012). In vivo Wnt signaling tracing through a transgenic biosensor fish reveals novel activity domains. Dev Biol 366, 327-340.

Moya, N., Cutts, J., Gaasterland, T., Willert, K., and Brafman, David A. (2014). Endogenous WNT Signaling Regulates hPSC-Derived Neural Progenitor Cell Heterogeneity and Specifies Their Regional Identity. Stem Cell Reports 3, 1015-1028.

Murayama, E., Kissa, K., Zapata, A., Mordelet, E., Briolat, V., Lin, H.-F., Handin, R.I., and Herbomel, P. (2006). Tracing Hematopoietic Precursor Migration to Successive Hematopoietic Organs during Zebrafish Development. Immunity 25, 963-975.

Nakamura, T., Mito, T., Miyawaki, K., Ohuchi, H., and Noji, S. (2008). EGFR signaling is required for re-establishing the proximodistal axis during distal leg regeneration in the cricket Gryllus bimaculatus nymph. Dev Biol 319, 46-55.

Ng, E.S., Davis, R., Stanley, E.G., and Elefanty, A.G. (2008). A protocol describing the use of a recombinant protein-based, animal product-free medium (APEL) for human embryonic stem cell differentiation as spin embryoid bodies. Nature Protocols 3, 768-776.

Ng, E.S., Davis, R.P., Azzola, L., Stanley, E.G., and Elefanty, A.G. (2005). Forced aggregation of defined numbers of human embryonic stem cells into embryoid bodies fosters robust, reproducible hematopoietic differentiation. Blood 106, 1601-1603.

North, T.E., Goessling, W., Walkley, C.R., Lengerke, C., Kopani, K.R., Lord, A.M., Weber, G.J., Bowman, T.V., Jang, I.H., Grosser, T., et al. (2007). Prostaglandin E2 regulates vertebrate haematopoietic stem cell homeostasis. Nature 447, 1007-1011.

Osherov, N., and Levitzki, A. (1994). Epidermal-growth-factor-dependent activation of the srcfamily kinases. Eur J Biochem 225, 1047-1053.

Pardanaud, L., Luton, D., Prigent, M., Bourcheix, L.M., Catala, M., and Dieterlen-Lievre, F. (1996). Two distinct endothelial lineages in ontogeny, one of them related to hemopoiesis.

Development 122, 1363-1371.

Parton, R.G., and Simons, K. (2007). The multiple faces of caveolae. Nat Rev Mol Cell Biol 8, 185-194.

Paul, I., Bhattacharya, S., Chatterjee, A., and Ghosh, M.K. (2013). Current Understanding on EGFR and Wnt/beta-Catenin Signaling in Glioma and Their Possible Crosstalk. Genes Cancer 4, 427-446.

Peng, J., Elias, J.E., Thoreen, C.C., Licklider, L.J., and Gygi, S.P. (2003). Evaluation of multidimensional chromatography coupled with tandem mass spectrometry (LC/LC-MS/MS) for large-scale protein analysis: the yeast proteome. J Proteome Res 2, 43-50.

Pereira, C.F., Chang, B., Qiu, J., Niu, X., Papatsenko, D., Hendry, C.E., Clark, N.R., NomuraKitabayashi, A., Kovacic, J.C., Ma'ayan, A., et al. (2013). Induction of a hemogenic program in mouse fibroblasts. Cell Stem Cell 13, 205-218. 
Pinson, K.I., Brennan, J., Monkley, S., Avery, B.J., and Skarnes, W.C. (2000). An LDLreceptor-related protein mediates Wnt signalling in mice. Nature 407, 535-538.

Prenzel, N., Zwick, E., Daub, H., Leserer, M., Abraham, R., Wallasch, C., and Ullrich, A. (1999). EGF receptor transactivation by G-protein-coupled receptors requires metalloproteinase cleavage of proHB-EGF. Nature 402, 884-888.

Pulecio, J., Nivet, E., Sancho-Martinez, I., Vitaloni, M., Guenechea, G., Xia, Y., Kurian, L., Dubova, I., Bueren, J., Laricchia-Robbio, L., et al. (2014). Conversion of human fibroblasts into monocyte-like progenitor cells. Stem Cells 32, 2923-2938.

Purba, E.R., Saita, E.I., and Maruyama, I.N. (2017). Activation of the EGF Receptor by Ligand Binding and Oncogenic Mutations: The "Rotation Model". Cells 6.

Ranheim, E.A., Kwan, H.C., Reya, T., Wang, Y.K., Weissman, I.L., and Francke, U. (2005). Frizzled 9 knock-out mice have abnormal B-cell development. Blood 105, 2487-2494.

Reya, T., Duncan, A.W., Ailles, L., Domen, J., and Scherer, D.C. (2003). A role for Wnt signaling in self-renewal of haematopoietic stem cells. Nature 423, 409.

Richter, J., Stanley, E.G., Ng, E.S., Elefanty, A.G., Traver, D., and Willert, K. (2018). WNT9A Is a Conserved Regulator of Hematopoietic Stem and Progenitor Cell Development. Genes (Basel) 9 .

Ring, L., Neth, P., Weber, C., Steffens, S., and Faussner, A. (2014). beta-Catenin-dependent pathway activation by both promiscuous "canonical" WNT3a-, and specific "noncanonical" WNT4- and WNT5a-FZD receptor combinations with strong differences in LRP5 and LRP6 dependency. Cell Signal 26, 260-267.

Rowlinson, J.M., and Gering, M. (2010). Hey2 acts upstream of Notch in hematopoietic stem cell specification in zebrafish embryos. Blood 116, 2046-2056.

Rulifson, E.J., Wu, C.H., and Nusse, R. (2000). Pathway specificity by the bifunctional receptor frizzled is determined by affinity for wingless. Mol Cell 6, 117-126.

Ryan, M.A., Nattamai, K.J., Xing, E., Schleimer, D., Daria, D., Sengupta, A., Kohler, A., Liu, W., Gunzer, M., Jansen, M., et al. (2010). Pharmacological inhibition of EGFR signaling enhances G-CSF-induced hematopoietic stem cell mobilization. Nat Med 16, 1141-1146. Saito-Diaz, K., Benchabane, H., Tiwari, A., Tian, A., Li, B., Thompson, J.J., Hyde, A.S., Sawyer, L.M., Jodoin, J.N., Santos, E., et al. (2018). APC Inhibits Ligand-Independent Wnt Signaling by the Clathrin Endocytic Pathway. Dev Cell 44, 566-581 e568.

Sandler, V.M., Lis, R., Liu, Y., Kedem, A., James, D., Elemento, O., Butler, J.M., Scandura, J.M., and Rafii, S. (2014). Reprogramming human endothelial cells to haematopoietic cells requires vascular induction. Nature 511, 312-318.

Schafer, B., Gschwind, A., and Ullrich, A. (2004). Multiple G-protein-coupled receptor signals converge on the epidermal growth factor receptor to promote migration and invasion. Oncogene 23, 991-999.

Schefe, J.H., Lehmann, K.E., Buschmann, I.R., Unger, T., and Funke-Kaiser, H. (2006). Quantitative real-time RT-PCR data analysis: current concepts and the novel "gene expression's CT difference" formula. J Mol Med (Berl) 84, 901-910.

Scheller, M., Huelsken, J., Rosenbauer, F., Taketo, M.M., and Birchmeier, W. (2006). Hematopoietic stem cell and multilineage defects generated by constitutive beta-catenin activation. Nat Immunol 10, 1038.

Schepers, A., and Clevers, H. (2012). Wnt signaling, stem cells, and cancer of the gastrointestinal tract. Cold Spring Harb Perspect Biol 4, a007989. 
Schweizer, L., and Varmus, H. (2003). Wnt/Wingless signaling through beta-catenin requires the function of both LRP/Arrow and frizzled classes of receptors. BMC Cell Biol 4, 4.

Shafer, B., Onishi, K., Lo, C., Colakoglu, G., and Zou, Y. (2011). Vangl2 promotes Wnt/planar cell polarity-like signaling by antagonizing Dvl1-mediated feedback inhibition in growth cone guidance. Dev Cell 20, 177-191.

Sheldahl, L.C., Park, M., Malbon, C.C., and Moon, R.T. (1999). Protein kinase C is differentially stimulated by Wnt and Frizzled homologs in a G-protein-dependent manner. Curr Biol 9, 695698.

Sibilia, M., and Wagner, E.F. (1995). Strain-dependent epithelial defects in mice lacking the EGF receptor. Science 269, 234-238.

Sievers, F., Wilm, A., Dineen, D., Gibson, T.J., Karplus, K., Li, W., Lopez, R., McWilliam, H., Remmert, M., Soding, J., et al. (2011). Fast, scalable generation of high-quality protein multiple sequence alignments using Clustal Omega. Mol Syst Biol 7, 539.

Slusarski, D.C., Corces, V.G., and Moon, R.T. (1997). Interaction of Wnt and a Frizzled homologue triggers G-protein-linked phosphatidylinositol signalling. Nature 390, 410-413. Sotgia, F., Williams, T.M., Cohen, A.W., Minetti, C., Pestell, R.G., and Lisanti, M.P. (2005). Caveolin-1-deficient mice have an increased mammary stem cell population with upregulation of Wnt/beta-catenin signaling. Cell Cycle 4, 1808-1816.

Sturgeon, C.M., Ditadi, A., Clarke, R.L., and Keller, G. (2013). Defining the path to hematopoietic stem cells. Nat Biotechnol 31, 416-418.

Sugimura, R., Jha, D.K., Han, A., Soria-Valles, C., da Rocha, E.L., Lu, Y.F., Goettel, J.A., Serrao, E., Rowe, R.G., Malleshaiah, M., et al. (2017). Haematopoietic stem and progenitor cells from human pluripotent stem cells. Nature 545, 432-438.

Suzuki, M., Shigematsu, H., Nakajima, T., Kubo, R., Motohashi, S., Sekine, Y., Shibuya, K., Iizasa, T., Hiroshima, K., Nakatani, Y., et al. (2007). Synchronous alterations of Wnt and epidermal growth factor receptor signaling pathways through aberrant methylation and mutation in non small cell lung cancer. Clin Cancer Res 13, 6087-6092.

Tamai, K., Semenov, M., Kato, Y., Spokony, R., Liu, C., Katsuyama, Y., Hess, F., Saint-Jeannet, J.P., and He, X. (2000). LDL-receptor-related proteins in Wnt signal transduction. Nature 407, 530-535.

Tamplin, O.J., Durand, E.M., Carr, L.A., Childs, S.J., Hagedorn, E.J., Li, P., Yzaguirre, A.D., Speck, N.A., and Zon, L.I. (2015). Hematopoietic stem cell arrival triggers dynamic remodeling of the perivascular niche. Cell 160, 241-252.

Tauriello, D.V., Jordens, I., Kirchner, K., Slootstra, J.W., Kruitwagen, T., Bouwman, B.A., Noutsou, M., Rudiger, S.G., Schwamborn, K., Schambony, A., et al. (2012). Wnt/beta-catenin signaling requires interaction of the Dishevelled DEP domain and $\mathrm{C}$ terminus with a discontinuous motif in Frizzled. Proc Natl Acad Sci U S A 109, E812-820.

Thompson, A., Schafer, J., Kuhn, K., Kienle, S., Schwarz, J., Schmidt, G., Neumann, T., Johnstone, R., Mohammed, A.K., and Hamon, C. (2003). Tandem mass tags: a novel quantification strategy for comparative analysis of complex protein mixtures by MS/MS. Anal Chem 75, 1895-1904.

Thomson, J.A., Itskovitz-Eldor, J., Shapiro, S.S., Waknitz, M.A., Swiergiel, J.J., Marshall, V.S., and Jones, J.M. (1998). Embryonic stem cell lines derived from human blastocysts. Science 282, 1145-1147. 
Tomlins, S.A., Bolllinger, N., Creim, J., and Rodland, K.D. (2005). Cross-talk between the calcium-sensing receptor and the epidermal growth factor receptor in Rat-1 fibroblasts. Exp Cell Res 308, 439-445.

Turpen, J.B., Knudson, C.M., and Hoefen, P.S. (1981). The early ontogeny of hematopoietic cells studied by grafting cytogenetically labeled tissue anlagen: localization of a prospective stem cell compartment. Dev Biol 85, 99-112.

Ueno, K., Hirata, H., Hinoda, Y., and Dahiya, R. (2013). Frizzled homolog proteins, microRNAs and Wnt signaling in cancer. Int $\mathrm{J}$ Cancer 132, 1731-1740.

Vacca, F., Bagnato, A., Catt, K.J., and Tecce, R. (2000). Transactivation of the epidermal growth factor receptor in endothelin-1-induced mitogenic signaling in human ovarian carcinoma cells. Cancer Res 60, 5310-5317.

van Es, J.H., Haegebarth, A., Kujala, P., Itzkovitz, S., Koo, B.K., Boj, S.F., Korving, J., van den Born, M., van Oudenaarden, A., Robine, S., et al. (2012). A critical role for the Wnt effector Tcf4 in adult intestinal homeostatic self-renewal. Mol Cell Biol 32, 1918-1927.

Veeman, M.T., Slusarski, D.C., Kaykas, A., Louie, S.H., and Moon, R.T. (2003). Zebrafish prickle, a modulator of noncanonical Wnt/Fz signaling, regulates gastrulation movements. Current biology: CB 13, 680-685.

Villasenor, R., Kalaidzidis, Y., and Zerial, M. (2016). Signal processing by the endosomal system. Curr Opin Cell Biol 39, 53-60.

Voloshanenko, O., Gmach, P., Winter, J., Kranz, D., and Boutros, M. (2017). Mapping of WntFrizzled interactions by multiplex CRISPR targeting of receptor gene families. FASEB J.

Wahlster, L., and Daley, G.Q. (2016). Progress towards generation of human haematopoietic stem cells. Nat Cell Biol 18, 1111-1117.

Wehrli, M., Dougan, S.T., Caldwell, K., O'Keefe, L., Schwartz, S., Vaizel-Ohayon, D., Schejter, E., Tomlinson, A., and DiNardo, S. (2000). arrow encodes an LDL-receptor-related protein essential for Wingless signalling. Nature 407, 527-530.

Wilkinson, R.N., Pouget, C., Gering, M., Russell, A.J., Davies, S.G., Kimelman, D., and Patient, R. (2009). Hedgehog and Bmp polarize hematopoietic stem cell emergence in the zebrafish dorsal aorta. Developmental Cell 16, 909-916.

Willert, K., Brown, J.D., Danenberg, E., Duncan, A.W., Weissman, I.L., Reya, T., Yates, J.R., 3rd, and Nusse, R. (2003). Wnt proteins are lipid-modified and can act as stem cell growth factors. Nature 423, 448-452.

Wong, H.C., Bourdelas, A., Krauss, A., Lee, H.J., Shao, Y., Wu, D., Mlodzik, M., Shi, D.L., and Zheng, J. (2003). Direct binding of the PDZ domain of Dishevelled to a conserved internal sequence in the C-terminal region of Frizzled. Mol Cell 12, 1251-1260.

Xiao, Y., Hsiao, T.H., Suresh, U., Chen, H.I., Wu, X., Wolf, S.E., and Chen, Y. (2014). A novel significance score for gene selection and ranking. Bioinformatics 30, 801-807.

Yamaguchi, Y., Hearing, V.J., Itami, S., Yoshikawa, K., and Katayama, I. (2005). Mesenchymalepithelial interactions in the skin: aiming for site-specific tissue regeneration. J Dermatol Sci 40, 1-9.

Yamamoto, A., Nagano, T., Takehara, S., Hibi, M., and Aizawa, S. (2005). Shisa promotes head formation through the inhibition of receptor protein maturation for the caudalizing factors, Wnt and FGF. Cell 120, 223-235.

Yamamoto, H., Komekado, H., and Kikuchi, A. (2006). Caveolin is necessary for Wnt-3adependent internalization of LRP6 and accumulation of beta-catenin. Dev Cell 11, 213-223. 
Yamamoto, H., Sakane, H., Yamamoto, H., Michiue, T., and Kikuchi, A. (2008). Wnt3a and Dkk1 regulate distinct internalization pathways of LRP6 to tune the activation of beta-catenin signaling. Dev Cell 15, 37-48.

Yanfeng, W.A., Tan, C., Fagan, R.J., and Klein, P.S. (2006). Phosphorylation of frizzled-3. J Biol Chem 281, 11603-11609.

Yu, H., Ye, X., Guo, N., and Nathans, J. (2012). Frizzled 2 and frizzled 7 function redundantly in convergent extension and closure of the ventricular septum and palate: evidence for a network of interacting genes. Development 139, 4383-4394.

Zettervall, C.J., Anderl, I., Williams, M.J., Palmer, R., Kurucz, E., Ando, I., and Hultmark, D. (2004). A directed screen for genes involved in Drosophila blood cell activation. Proc Natl Acad Sci U S A 101, 14192-14197.

Zhang, X.Y., and Rodaway, A.R. (2007). SCL-GFP transgenic zebrafish: in vivo imaging of blood and endothelial development and identification of the initial site of definitive hematopoiesis. Dev Biol 307, 179-194.

Zhang, Y., Jiang, Q., Kong, X., Yang, L., Hu, W., Lv, C., and Li, Y. (2016). Methylation status of the promoter region of the human frizzled 9 gene in acute myeloid leukemia. Mol Med Rep $14,1339-1344$.

Zhao, C., Blum, J., Chen, A., Kwon, H.Y., Jung, S.H., Cook, J.M., Lagoo, A., and Reya, T. (2007). Loss of $\beta$-Catenin Impairs the Renewal of Normal and CML Stem Cells In Vivo. Cancer Cell 12, 528-541.

Zhao, Y., and Lin, S. (2013). Essential role of SH3-domain GRB2-like 3 for vascular lumen maintenance in zebrafish. Arterioscler Thromb Vasc Biol 33, 1280-1286.

Zhen, F., Lan, Y., Yan, B., Zhang, W., and Wen, Z. (2013). Hemogenic endothelium specification and hematopoietic stem cell maintenance employ distinct Scl isoforms. Development (Cambridge, England) 140, 3977-3985.

Zhou, Y., and Nathans, J. (2014). Gpr124 controls CNS angiogenesis and blood-brain barrier integrity by promoting ligand-specific canonical wnt signaling. Dev Cell 31, 248-256.

Zovein, A.C., Hofmann, J.J., Lynch, M., French, W.J., Turlo, K.A., Yang, Y., Becker, M.S., Zanetta, L., Dejana, E., Gasson, J.C., et al. (2008). Fate tracing reveals the endothelial origin of hematopoietic stem cells. Cell stem cell 3, 625-636. 
Figure 2: Fzd9b is required for zebrafish hematopoietic stem cell development.

A

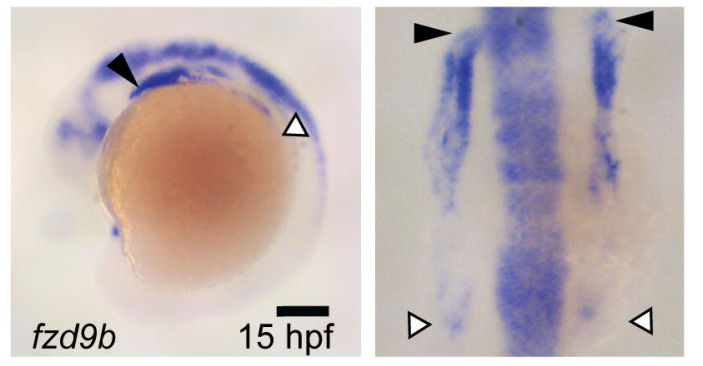

fzd9b:Gal4;UAS:GFP
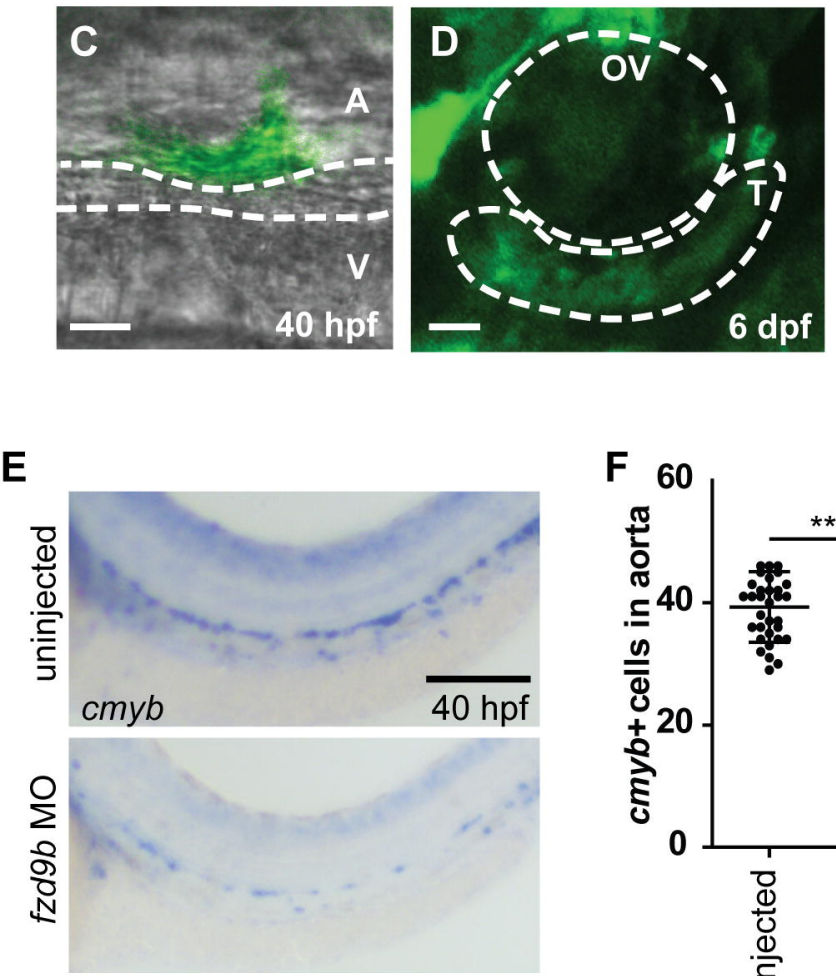

I

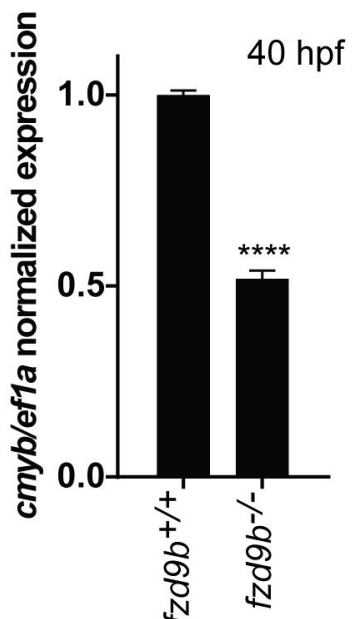

B

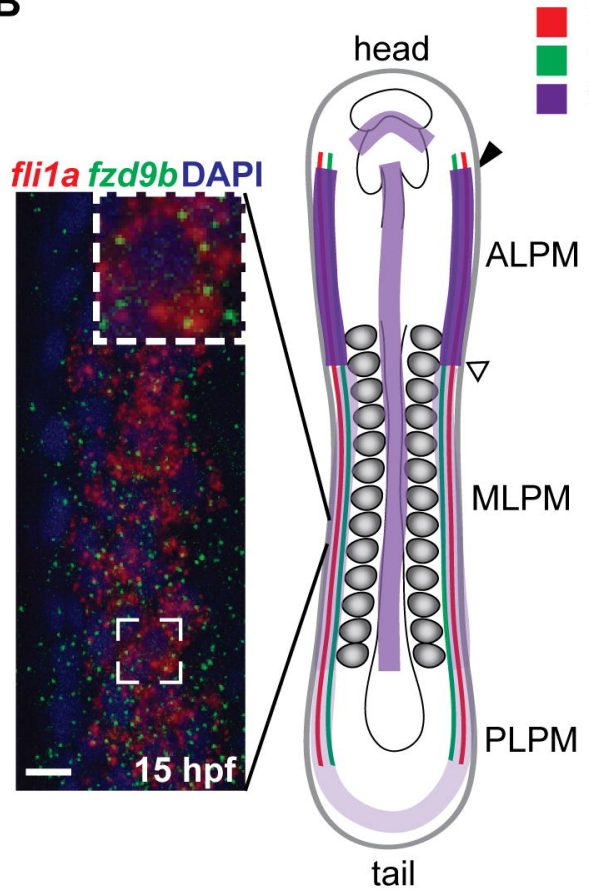

ALPM hematopoietic precursors vascular precursors $f z d 9 b$ expression

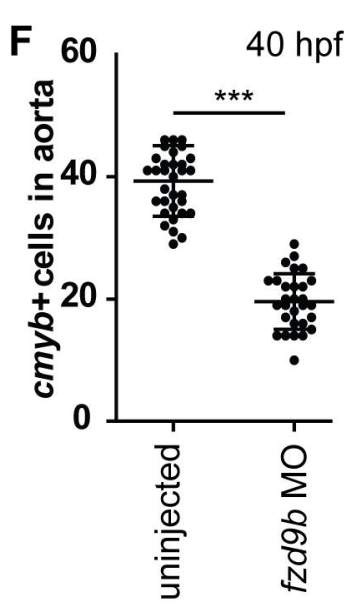

H

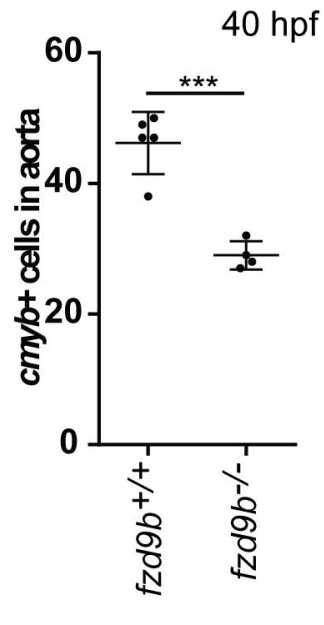

J

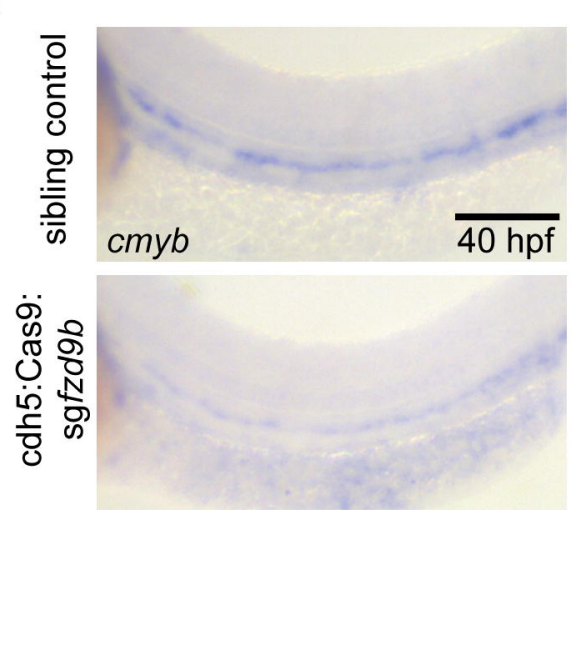

K

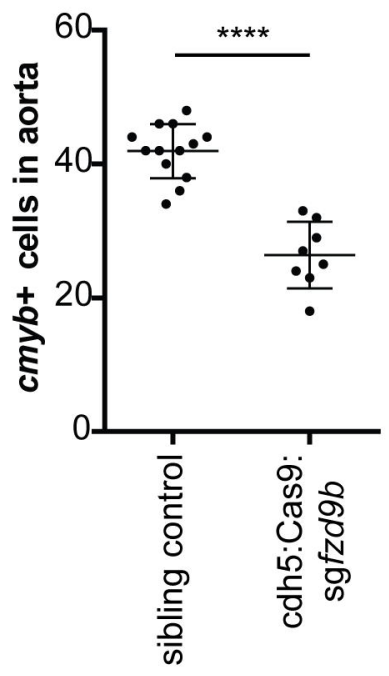


Figure 3: Fzd9b interacts genetically with Wnt9a.

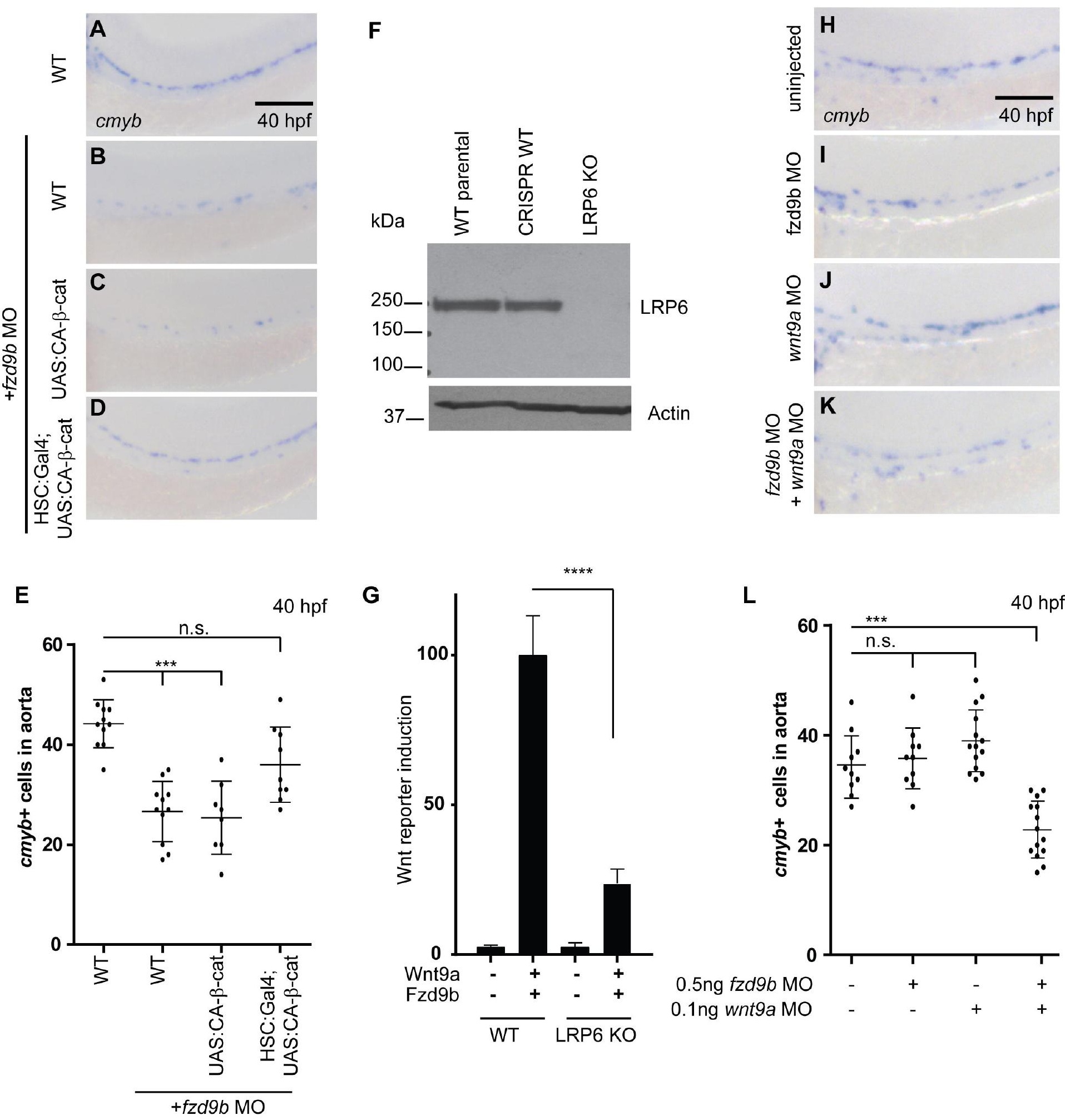


A

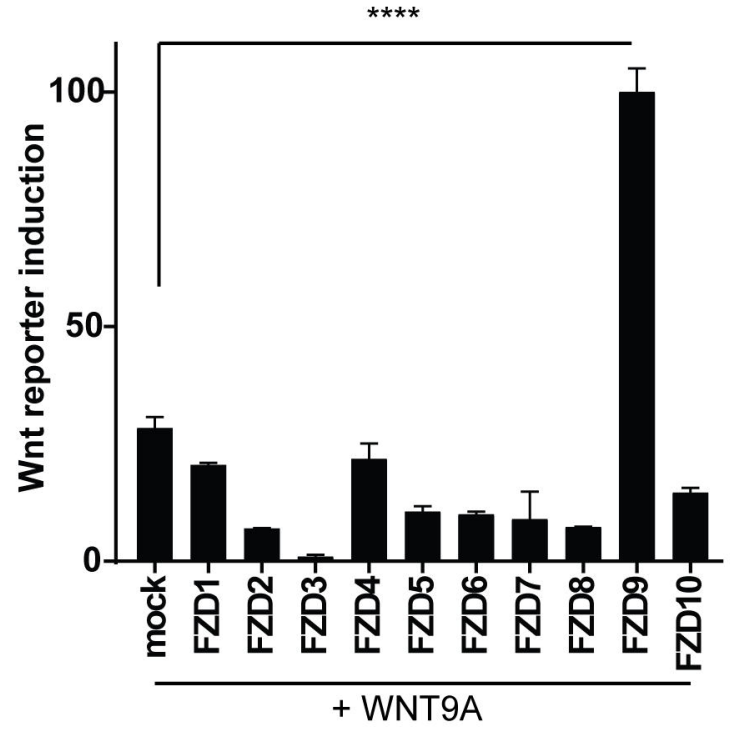

C

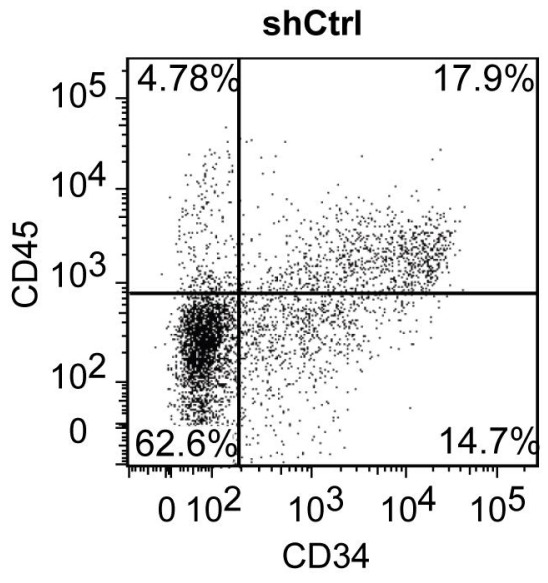

E

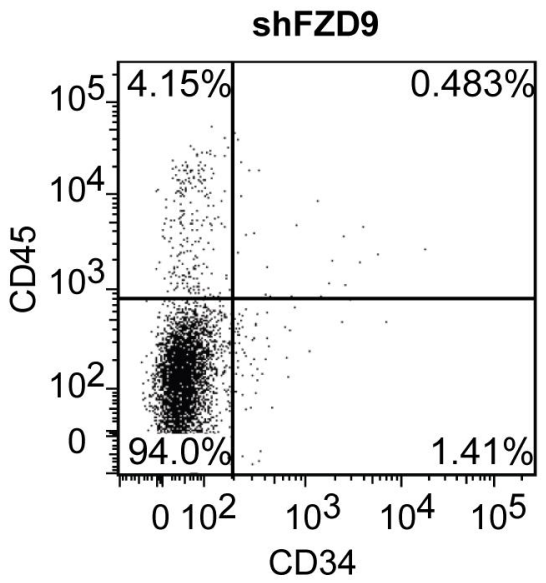

F
B

hESCs

$\downarrow$

shRNA virus and selection

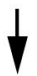

Spin EB

HSPC differentiation

CD34+/CD45+ Flow Cytometry or qPCR
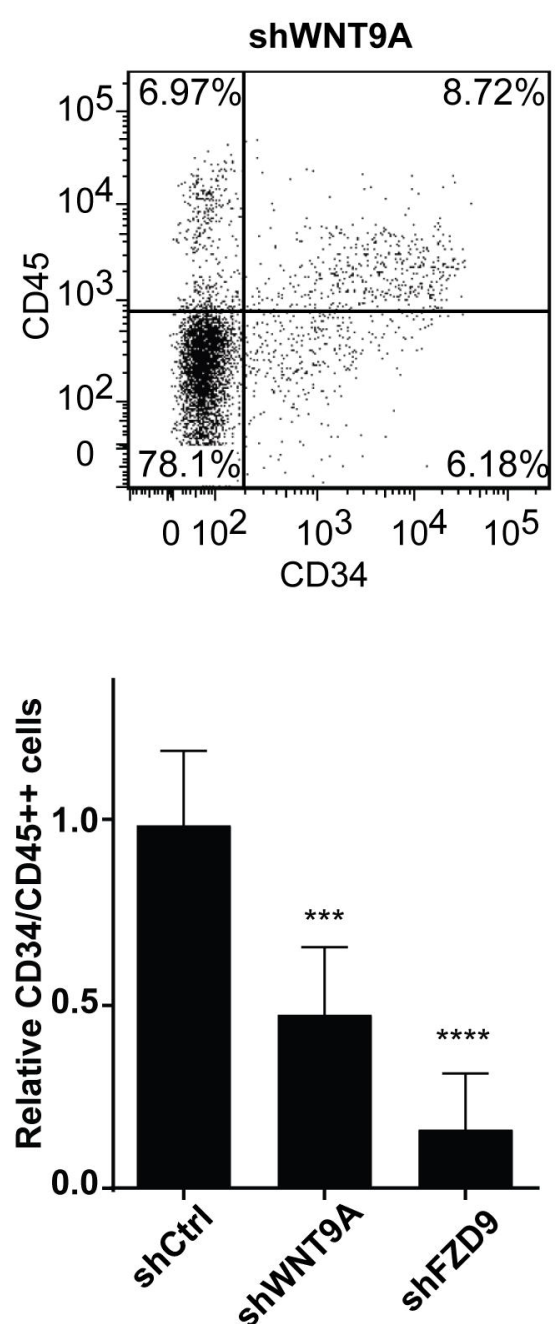
Figure 5: Wnt9a-Fzd9b specificity is mediated intracellularly

A

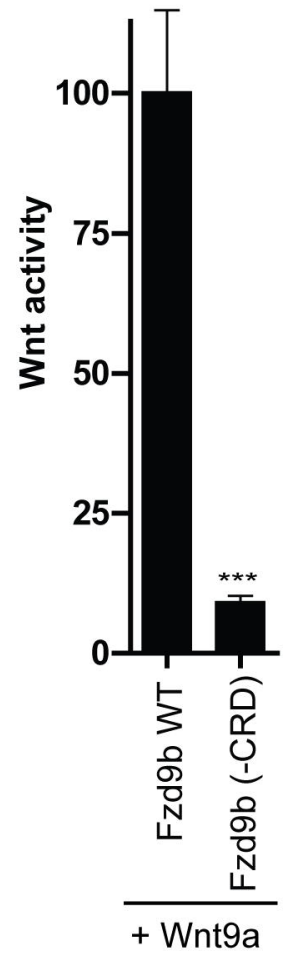

B

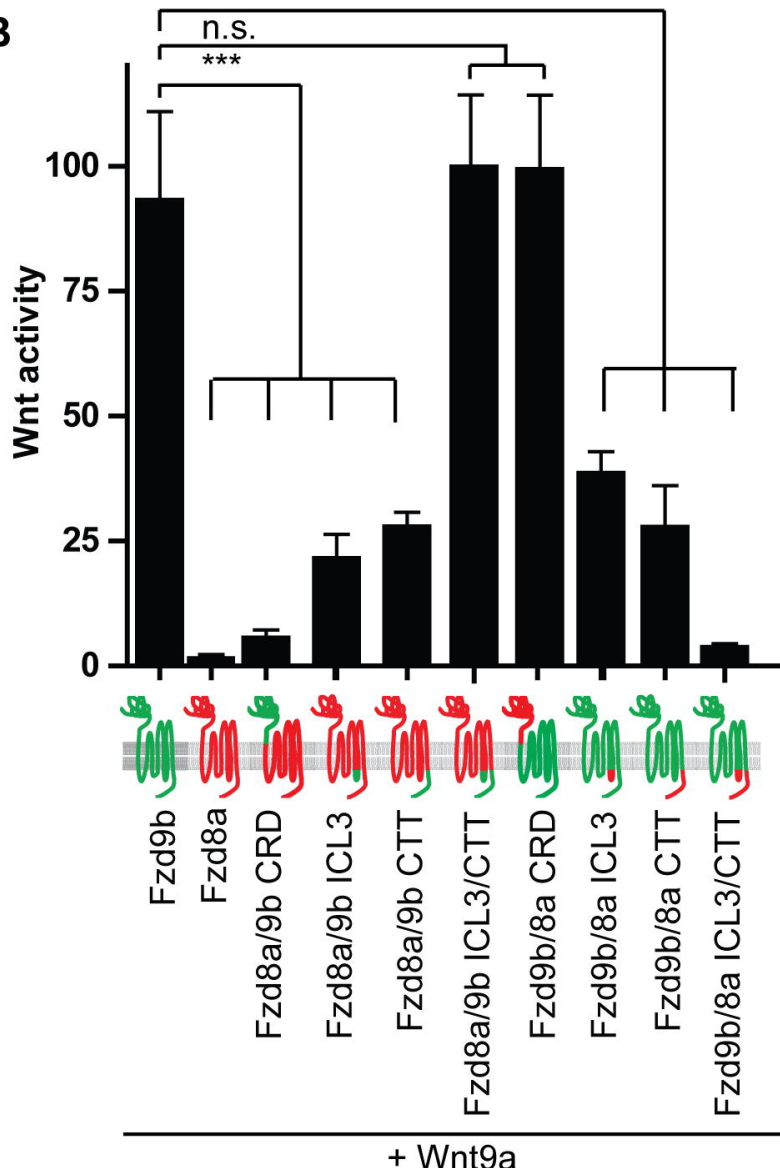

H
mRNA:

none

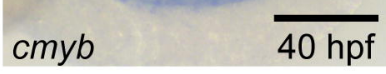

D

none

E

$f z d 9 b$

F

fzd8a

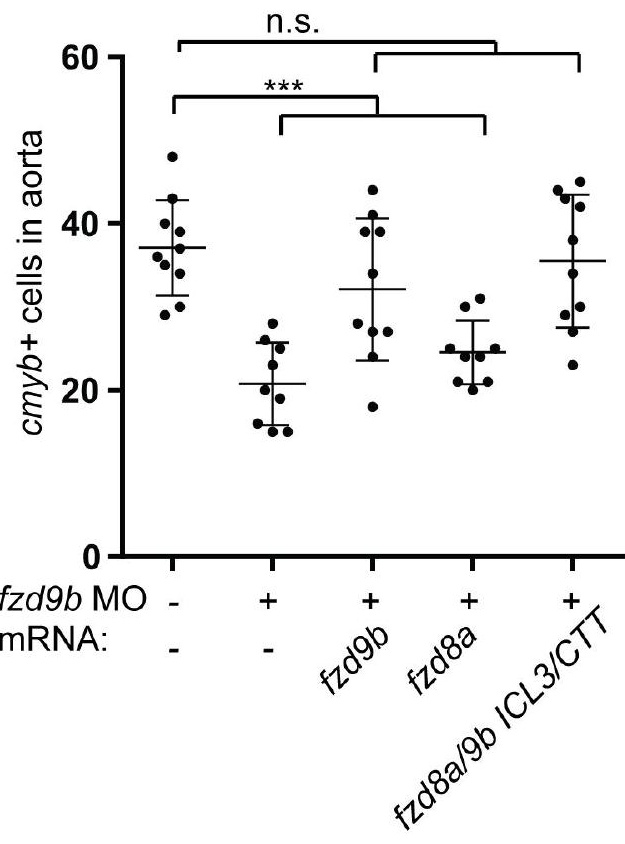


Figure 6: EGFR mediates Wnt9a-Fzd9b signaling
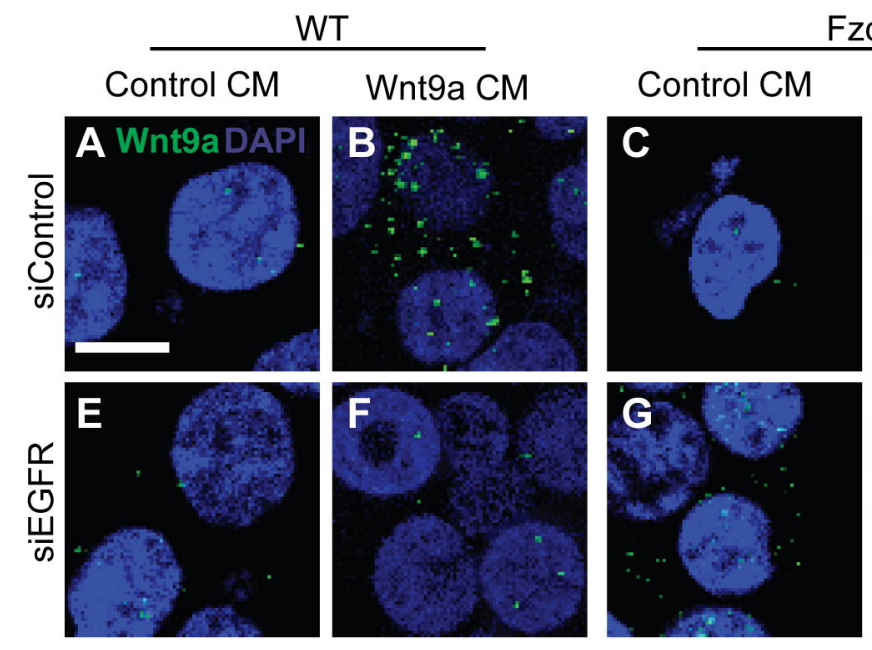

Fzd9b

K

L

zebrafish
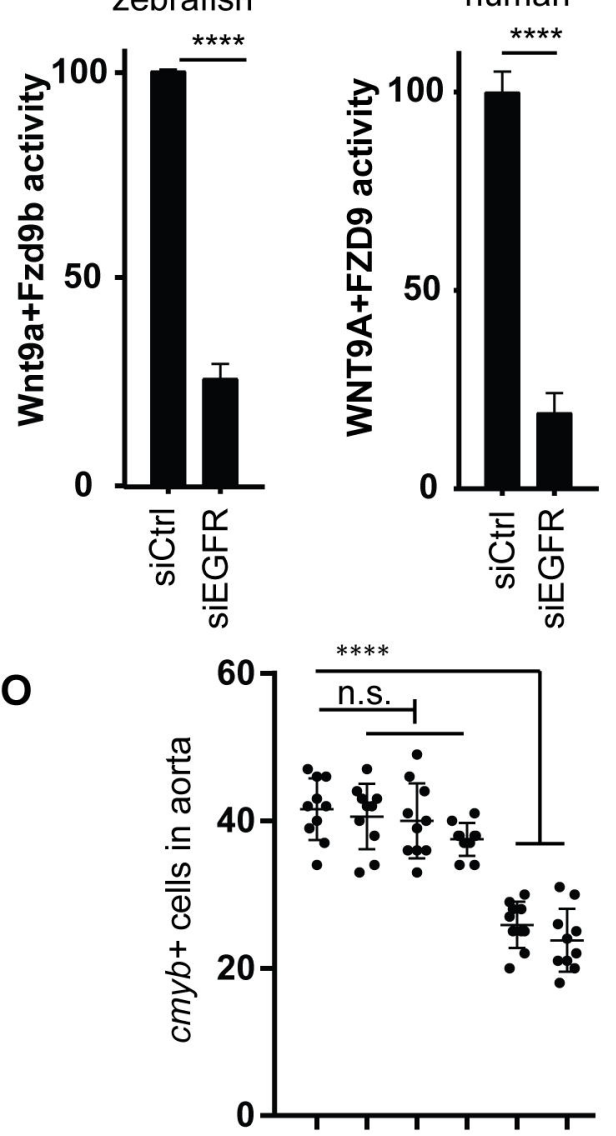

$0.5 \mathrm{ng}$ fzd $9 \mathrm{~b} \mathrm{MO}$

$0.1 \mathrm{ng}$ wnt $9 \mathrm{a} \mathrm{MO}$

1 ng egfra MO

$\mathbf{R}$

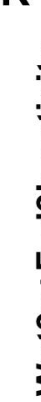

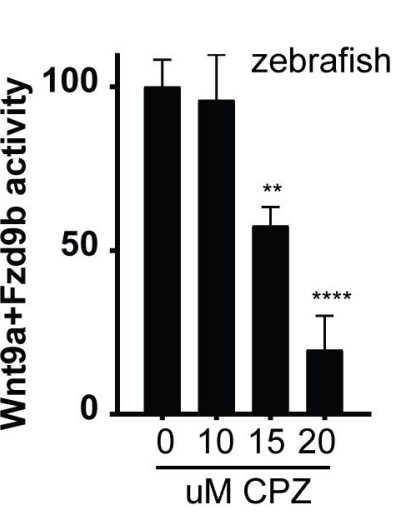

S

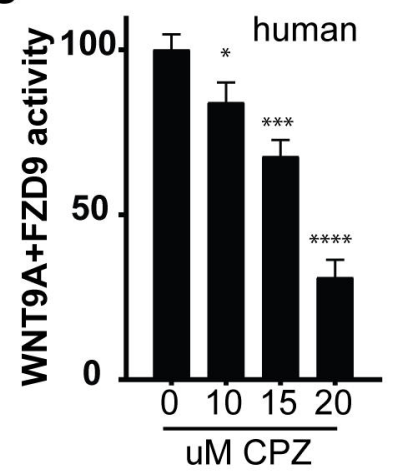

Wnt9a CM
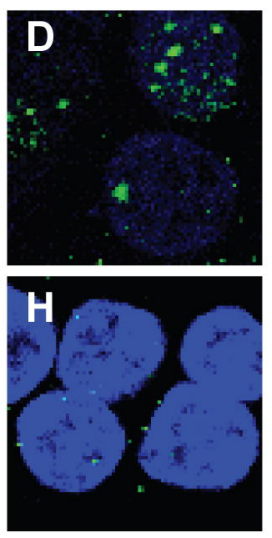

M

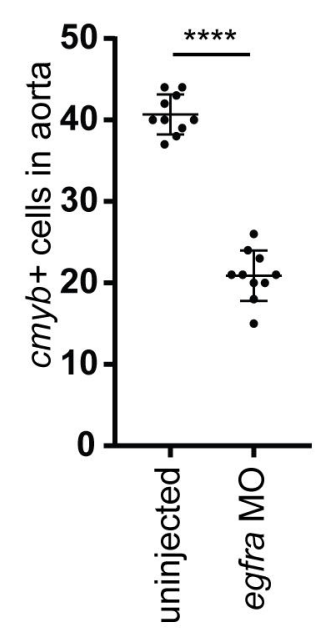

Wnt9a Tx

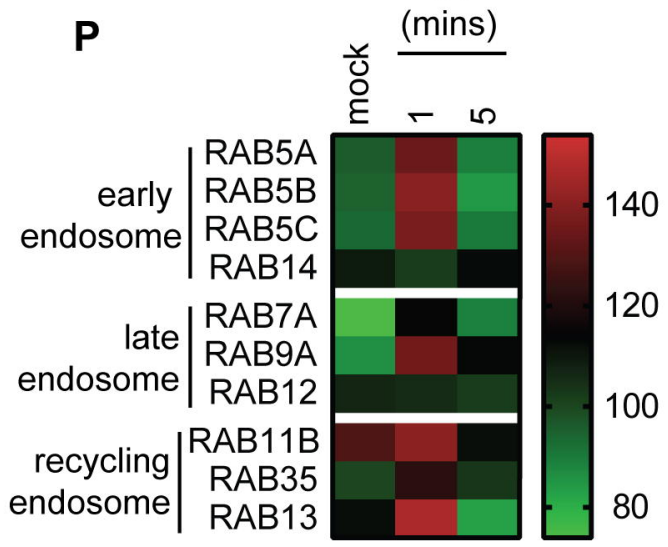

Q
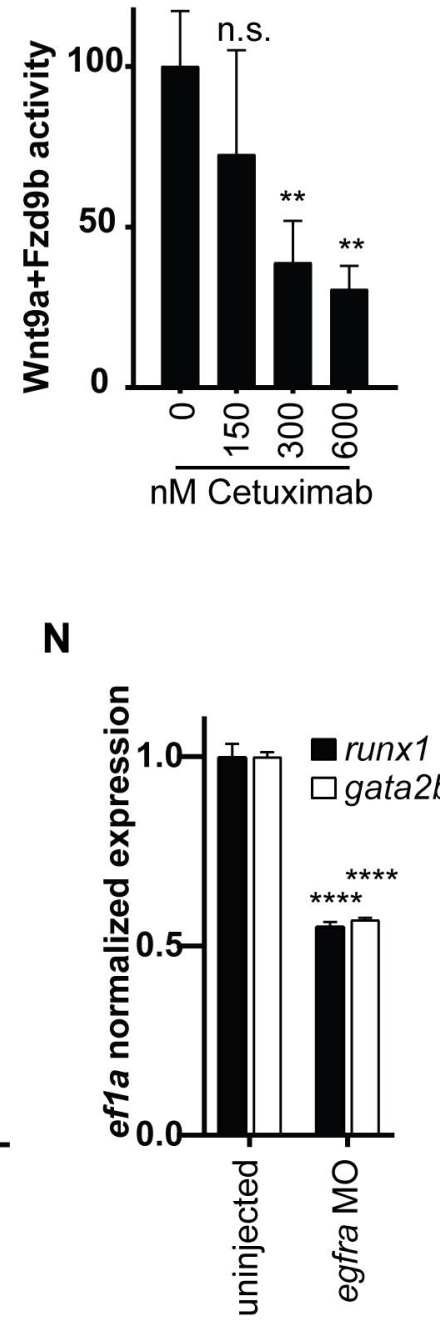

$\mathbf{N}$

\section{Wnt9a Tx}

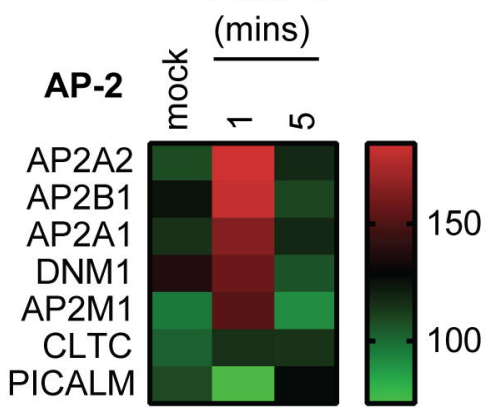


Figure 7: Fzd9b Tyrosine phosphorylation is required for Wnt9a-Fzd9b signaling.

A

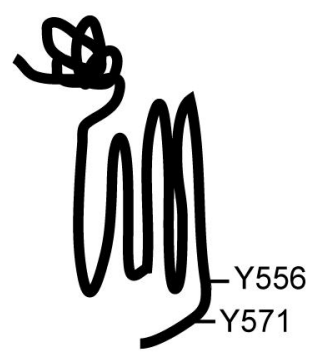

(i)

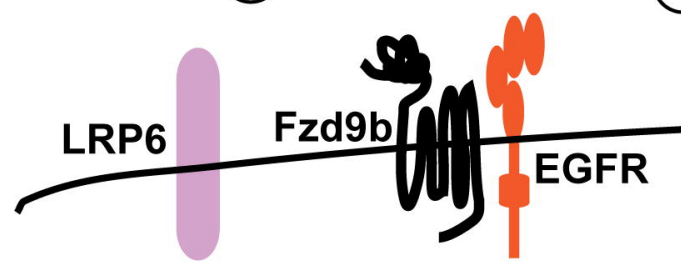

(ii) Destruction Complex
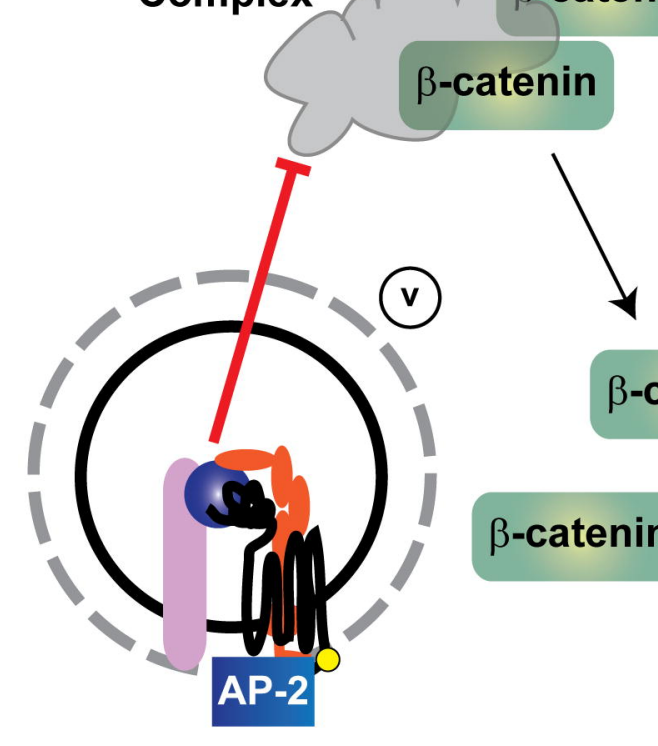

$\beta$-catenin
B Tx: $\frac{\text { IB: Fzd9b }}{\text { mock Wnt9a }} \frac{\text { Fzd9b-mKate }}{\text { mock Wnt9a }} \mathrm{kDa}$

$1 \%$ input

IP: pTyr
$-100$

$-100$

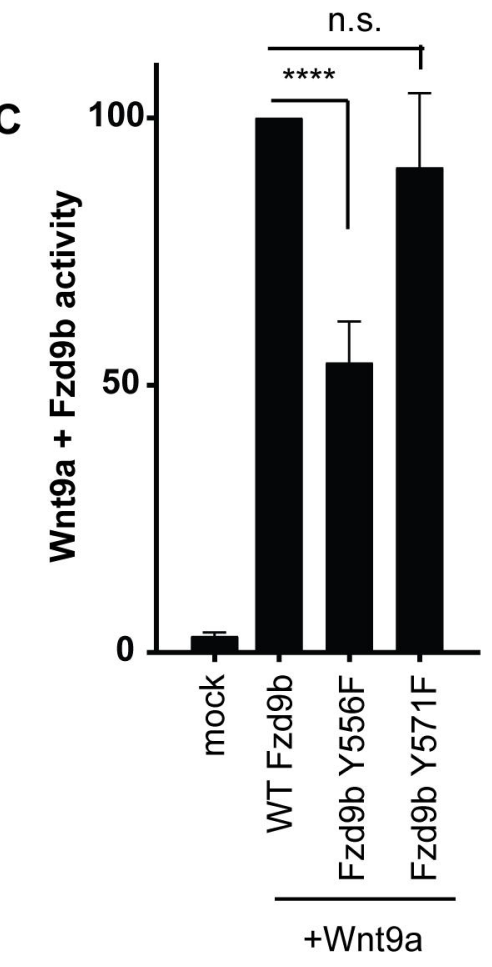

(iii) Wnt9a

proteasome $p-Y$

(iv)

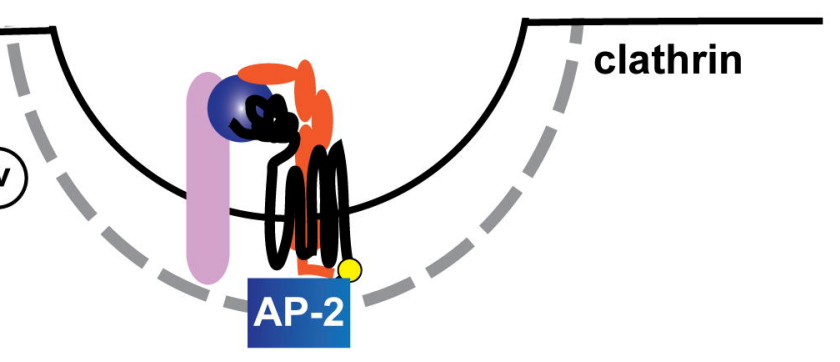

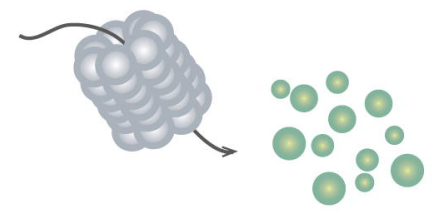

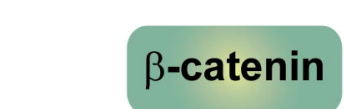

(vi)

Wnt9a/Fzd9b targets HSC proliferation 